\title{
RESPONSABILIDAD POR INCUMPLIMIENTO DE CONTRATOS DE SERVICIOS. LA PROTECCIÓN DEL CONSUMIDOR Y DEL CLIENTE POR PRESTACIONES DEFECTUOSAS
}

\author{
LIABILITY FOR BREACH OF WARRANTY IN SERVICE CONTRACTS: \\ CONSUMER AND CLIENT PROTECTION FOR FAILURE TO COMPLY
}

\author{
María Sara Rodríguez Pinto*
}

\begin{abstract}
RESUMEN: La responsabilidad o garantía legal del proveedor por el incumplimiento de contratos de prestación de servicios tiene un estatuto análogo al del vendedor en la compraventa. Se trata de un conjunto de sanciones o medios de tutela del acreedor del servicio frente al incumplimiento, por los que puede optar o en algunos casos acumular. Estos son: la resolución del contrato o devolución del precio, el cumplimiento o la reiteración del servicio y la indemnización de perjuicios. Estas sanciones son congruentes con las singularidades de contratos que engendran obligaciones de hacer, como los servicios de resultado; y funcionan todos sobre el presupuesto del incumplimiento total o parcial, o frente al cumplimiento tardío del deudor. La imputabilidad del incumplimiento a culpa o dolo del deudor no tiene más relevancia que para el último de los medios nombrados: la indemnización de perjuicios. El deudor o prestador del servicio no puede, por tanto, exonerarse de responsabilidad por caso fortuito o fuerza mayor; y ni siquiera por imposibilidad sobreviniente de la prestación. El derecho común y de consumidores se integran y complementan en este ámbito, ofreciendo un sistema de garantía o responsabilidad en gran parte común a todos los contratos de servicios.
\end{abstract}

Palabras clave: Contratos de prestación de servicios, incumplimiento, responsabilidad, garantía, derecho del consumo, falta de conformidad.

ABSTRACT: Liability for breach of warranty in service contracts has a similar status to that of the breach of sales contracts. It consists of a set of remedies the creditor has against the breaching provider of services, among which he may choose or in some cases accumulate. These are: rescission of contract or restitution of price, specific performance or reiteration of the service, and compensation for damages. These remedies are consistent with the singularities of service contracts, as contracts that create obligations to do, as those of service contracts result; and all work on the assumption of a total or partial failure, or late performance. The attribution of failure to negligence or fraud of the debtor has no relevance save to the last of the remedies mentioned: compensation for damages. The debtor or service provider cannot therefore be exempted from liability for acts of God or force majeure, and not even by supervening impossibility of performance. The common law and consumer law are integrated and complement in this area, offering a warranty or system of liability largely common to all service contracts.

Key words: Service contracts, remedies for breach of warranty, breach of contracts, consumer law, disconformity to contract.

* Licenciada (Pontificia Universidad Católica de Chile, 1988); LL.M. (Northwestern University, 1997); Doctora (Universidad Autónoma de Madrid, 2004). Profesora de Derecho Civil en la Facultad de Derecho de la Universidad de los Andes. Correo electrónico: msrodriguez@uandes.cl. Este trabajo es un producto del Proyecto Fondecyt Regular No 1100804 . 


\section{INTRODUCCIÓN}

Este artículo defiende la proposición de que la responsabilidad civil por el incumplimiento de contratos de servicios consiste en una garantía legal análoga a la de la compraventa porque la mayor parte de los servicios se contrata en vistas de un resultado. Esta garantía está formada por los siguientes remedios: resolución del contrato o devolución del precio, cumplimiento o repetición de la prestación debida, e indemnización de perjuicios.

Se trabaja en torno a la hipótesis de un sistema de protección legal del acreedor idéntico para servicios civiles o mercantiles y servicios al consumidor, aunque las fuentes difieran. Este propósito exige conectar el tratamiento general de la responsabilidad civil por incumplimiento de contratos (artículos 1489, 1553 y 1556 a 1558 del Código Civil chileno) con varias normas de lo que podríamos llamar parte especial del Código Civil chileno (comprendidas en los Títulos XXVI a XXXII del Libro IV). Requiere también relacionar todo esto con las normas de la ley $\mathrm{N}^{\circ}$ 19.496, de 1997, sobre protección de los derechos de los consumidores (en adelante también LPC). La LPC considera un sistema de sanciones para el caso específico de incumplimiento de contratos de servicios en el Título III, Párrafo $4^{\circ}$, bajo el título "Normas especiales en materia de prestación de servicios" (artículos 40 a 43). Hasta ahora no se ha abordado el estudio de la responsabilidad contractual que emerge del incumplimiento de servicios, a clientes en general y a consumidores. Este estudio asume este desafío y propone un aporte de sistematización a esta discusión.

El objeto que se propone reviste interés pues los contratos de servicios son negocios jurídicos en expansión. El 11 de noviembre de 2011, El Mercurio Legal informaba que de 13 demandas colectivas presentadas ese año por el Servicio Nacional del Consumidor (en adelante también Sernac), 10 fueron contra empresas de servicios básicos y de espectáculos por incumplimientos de diversa índole que afectaban a consumidores ${ }^{1}$. En esa misma nota se señalaba que el mercado que lideraba reclamos por incumplimiento de servicios era el financiero, con 50.269 reclamos a esa fecha ${ }^{2}$. El crecimiento de la importancia de estos contratos se empieza a reflejar en un aumento de estudios analíticos en castellano ${ }^{3}$, propuestas legislativas a todo nivel ${ }^{4}$; y en una nutrida e interesante jurisprudencia.

Este estudio parte de un concepto de "responsabilidad" que consiste en la sanción o consecuencias jurídicas que produce la infracción del contrato. Tradicionalmente se enseña en Chile que esta responsabilidad consiste en "la obligación de indemnizar al acreedor el perjuicio que le causa el incumplimiento del contrato o su cumplimiento tardío o imperfecto" 5 . Pero en el ámbito de los contratos, el perjuicio del acreedor puede quedar indemne o ser

\footnotetext{
1 El Mercurio Legal, 11 de noviembre de 2011, "76\% de las demandas colectivas del Sernac son contra mercados de servicios básicos y de espectáculos este 2011", disponible en: www.elmercuriolegal.com/Noticias/ Noticia-y-reportajes/2011/11/10 (visitado el 11 de noviembre de 2011).

2 A esta situación responde en general la ley $\mathrm{N}^{\circ} 20.555$, de 5 de diciembre de 2011, para dotar de atribuciones en el ámbito de productos y servicios financieros al Sernac (ley también conocida como "Sernac financiero").

3 Barros (2011) pp. 326-340; Parra (2011); Contardo (2010); Barrientos (2010) pp. 39-73; Villanueva (2009a); Villanueva (2009b); Ortí (2006).

4 Service Contracts (PEL SC) (2007); Directiva 2006/123/CE relativa a los servicios en el mercado interior.

5 Alessandri (2005) n. 24.
} 
compensado de diferentes modos. Usando una terminología aceptada por autores nacionales, el incumplimiento se subsana con diversos "remedios", que operarían en la práctica como un sistema aunque carezcan de coherencia normativa ${ }^{6}$. Según el artículo 1489 el acreedor puede optar por exigir el cumplimiento (en naturaleza o específico), o la resolución del contrato no cumplido; en cualquiera de los dos casos, con indemnización de perjuicios. Es decir, el acreedor puede quedar indemne por el valor de prestación en sí mismo (en naturaleza o por equivalente) o por la restitución del precio pagado por la prestación no cumplida; partidas compensatorias del incumplimiento a las que el acreedor podría añadir los llamados perjuicios consecuenciales $^{7}$, que se tiende a defender que consisten en el interés positivo del acreedor (al menos en el supuesto de la acumulación de resolución e indemnización) ${ }^{8}$. Por su parte, el artículo 41 LPC dispone que en caso de incumplimiento de un contrato de prestación de servicios el consumidor (acreedor del servicio) puede exigir que "se preste nuevamente el servicio" (una pretensión de cumplimiento) o "la devolución del precio pagado por este al proveedor" (una consecuencia de la resolución); quedando siempre a salvo la posibilidad de exigir la indemnización de todo perjuicio. Es decir, la serie de sanciones que ofrece la LPC puede considerarse equivalente a la que ofrece el Código Civil.

Por tanto, se defiende la idea de que la indemnización de perjuicios en el sentido pecuniario y compensatorio del concepto no es la única sanción que puede imponer el acreedor o consumidor del servicio al deudor. Sería incluso riesgoso afirmar que la única sanción frente al incumplimiento es la indemnización pues, fuera del ámbito de la LPC, todavía se discute en Chile si el acreedor debería pedir la indemnización en forma accesoria a otra petición principal ${ }^{9}$, aunque va consolidándose una lectura de las normas que favorece la autonomía de la indemnización de perjuicios ${ }^{10}$. En la LPC, la indemnización de "todos los daños materiales y morales en caso de incumplimiento de cualquiera de las obligaciones contraídas por el proveedor" es un derecho garantizado al consumidor por la misma ley (artículo $3^{\circ}$ letra $\left.e\right)$ ).

El desarrollo de las ideas expuestas anteriormente se hará de la siguiente forma. En primer lugar se examinarán algunas singularidades de los contratos de servicios, como contratos que engendran obligaciones de hacer. En esta parte también se procura aportar a la reconstrucción de un régimen de los contratos de prestación de servicios en general (Parte I.). En segundo lugar se examinará el presupuesto de la responsabilidad contractual: el incumplimiento. El objetivo es demostrar que el hecho del incumplimiento tiene de por sí unas sanciones; y su imputabilidad, otras. Advertimos que esta parte no tiene por objeto realizar nuevos aportes sino el ofrecer una síntesis del estado de la cuestión entre los autores chilenos. (Parte II.). En tercer lugar, el punto central de este estudio es la organización de las consecuencias jurídicas del incumplimiento de contratos de servicios, en cuanto contratos que engendran obligaciones de hacer (Parte III.). El artículo quedaría inconcluso sin

\footnotetext{
${ }^{6}$ Cfr. Vidal (2006) pp. 173-207; Pizarro (2008) p. 395.

7 Corral (2010) p. 155.

8 Por todos, recientemente, ConTARdo (2012) pp. 242-246.

9 Más recientemente, BaraOna (1997) p. 158.

10 Peñailillo (2006) p. 429; Vidal (2006), p. 198; López (2010) pp. 99-103 y jurisprudencia por ellos citada.
} 
la última parte, que aborda las posibles causas de exoneración en que podría ampararse el deudor de obligaciones de servicios (Parte IV.).

\section{LOS CONTRATOS DE SERVICIOS EN LA LEGISLACIÓN CHILENA}

Los contratos de servicios ofrecen diversas peculiaridades. Pero en esto la legislación chilena no es muy distinta a los ordenamientos jurídicos codificados. Se ha escrito que los servicios son "el cajón de sastre"11 y "el pariente pobre"12 de los contratos. Esto puede ser cierto en cuanto a que su marco regulatorio legal carece de la unidad sistemática de que goza la compraventa. Pero no lo es en el terreno del tráfico jurídico. Su importancia práctica exige un esfuerzo de caracterización que facilite el estudio de la responsabilidad por su incumplimiento.

Como punto de partida puede afirmarse que los servicios son contratos atípicos en el sentido tradicional de la palabra; es decir, no tienen un tratamiento sistemático en el Código Civil ni en el Código de Comercio. Se distinguen por ser contratos que engendran obligaciones de hacer. Es común encontrarlos inmersos en contratos complejos, vinculados con otros negocios de diversa naturaleza. Según las categorías de obligaciones de medio y resultado, los contratos de servicios pueden ser de una u otra clase, aunque predomina la contratación de servicios de resultado. Por último, a partir de la LPC, se puede afirmar que la gran clasificación de estos contratos procede de quienes resultan ser sus partes, pues los servicios a consumidores quedan sujetos a un régimen especial que los distingue de los demás servicios.

\section{A) Contratos innominados y atípicos, PERO CON TIPICIDAD SOCIAL O DE TRÁFICO}

Los contratos de servicios son contratos innominados o atípicos porque no tienen en el Código Civil o de Comercio un régimen especial como tales. La disciplina de este contrato debe reconstruirse a partir de normas dispersas en el Libro IV del Código Civil chileno, tales como las relativas al contrato de confección de obra (artículos 1996 a 2005), al arrendamiento de servicios inmateriales (artículos 2006 a 2012) y al arrendamiento de transporte (artículos 2013 a 2021). Hay que reconocer también la prestación de unos determinados servicios en el régimen del mandato (Título XXIV del Libro IV) y en el depósito remunerado, que según el artículo 2219 es un arrendamiento de servicios de custodia, artículos todos estos que aportan elementos normativos al contrato.

Por otra parte, la Ley 19.496 sobre protección de los derechos de los consumidores admite explícitamente la existencia de un contrato de "prestación de servicios" (Título III, Párrafo $4^{\circ}$, sobre Normas especiales en materia de prestación de servicios), como el servicio de reparación de cualquier tipo de bienes (cf. artículos 40, 41 y 42 LPC). También regula otros servicios a consumidores, como los servicios crediticios, de seguros y, en general, de cualquier producto financiero (especialmente, artículos 55 a 56H LPC) y la contratación (no el cumplimiento o incumplimiento) de servicios de enseñanza y de salud (artículo $2^{\circ}$ LPC). Es importante destacar que el Derecho chileno de consumidores no tipifica o siste-

\footnotetext{
11 Cfr. Villanueva (2009a) passim; Villanueva (2009b) passim.
}

12 Barros (2011) p. 326. 
matiza estos contratos, sino que se limita a regular determinados aspectos, como deberes de información, cláusulas abusivas en contratos de adhesión, mecanismos de solución de controversias y, en relación a este estudio, las consecuencias de su incumplimiento. Tenemos, entonces, que en Chile el de prestación de servicios podría ser calificado de contrato normativamente atípico pero nominado, pues posee un nombre por el que es conocido y usado ${ }^{13}$.

La tipicidad social ${ }^{14}$ del contrato queda bien reflejada en la jurisprudencia. A continuación ofrezco algunos ejemplos en los que distintos tribunales utilizan el nombre "prestación de servicios" para calificar una variedad de contratos. En Hiller con Comercial Bas S.A. (2008) se califica como prestación de servicios la reparación de artefactos de navegación. En una sentencia arbitral del Centro de Arbitraje y Mediación de Santiago (CAM Santiago) (2006) (Juan Eduardo Figueroa Valdés), se califica como un contrato de prestación de servicios el desarrollo, implementación y soporte técnico de un software computacional. En otra sentencia del CAM Santiago (2008), se califica como un contrato de servicios aquel por el cual el proveedor se obliga a ofrecer servicios de lavandería mediante máquinas instaladas en edificios habitacionales. Los servicios de diseño, construcción y habilitación de un local comercial son un contrato de prestación de servicios en Elizalde con Sociedad Comercial (2009). Otros ejemplos tomados de jurisprudencia más antigua citada como expresión del objeto de estos contratos son los siguientes ${ }^{15}$ : construir un edificio, transportar una mercadería, defender un pleito, abrir una calle en terrenos propios en beneficio de vecinos colindantes, transportar petróleo a un lugar convenido, prolongar, limpiar y ensanchar un canal. En el ámbito de protección al consumidor, se ha considerado en la práctica que son contratos de prestación de servicios los servicios de suministro de telefonía móvil (Jacob Jure con SmartCom PCS [2008]; Meneses con Bellsouth [2006]), los servicios de obras civiles entre particulares (Lobos con Allendes [2008], Moreira con Vera [2010]) (aunque estos contratos con dificultad pueden encontrarse cubiertos por la LPC), los servicios educacionales (Bravo con Preuniversitario Pedro de Valdivia, 2005).

Se ha reconocido que el contrato de viaje combinado es normativamente atípico pero con consecuencias en parte regladas. Su operación ha empezado a engendrar una cantidad considerable de litigios ${ }^{16}$. Otro caso que ha merecido estudio y pronunciamientos de los tribunales es el contrato de estacionamiento de vehículos en la vía pública, en centros comerciales y en instalaciones especialmente destinadas a este objeto ${ }^{17}$.

La atipicidad normativa del contrato de servicios ha llevado a $\operatorname{proponer}^{18}$ que los contratos de servicios que carecen de regulaciones normativas especiales deben entenderse normados analógicamente por las reglas del mandato; a menos que el resultado del servicio sea un riesgo del deudor, caso en el cual se aplica supletoriamente la normativa del arren-

13 López (1998) t. I, n. 25.

14 Sobre la existencia de una tipicidad social, categoría que parece haber introducido Betti en el Derecho, cfr. Díez-Picazo (1996) Cap. XIV.

15 Abeliuk (2008) n. 348.

16 Contardo (2010) pp. 5-40.

17 Cfr. Barrientos (2010) pp. 39-73.

18 Barros (2011) p. 331, quien apoya sus reflexiones en normas de los modernos códigos civiles de Holanda y Suiza, y en autores alemanes. 
damiento de obra material. El mandato (artículos 2116 a 2173 del Código Civil y artículos 233 a 317 del Código de Comercio) efectivamente aporta un cuerpo normativo profundo y potente para la integración e interpretación de los contratos de prestación de servicios. Sin embargo, desde el punto de vista de la responsabilidad del prestador u obligado pensamos que reviste mayor relevancia su caracterización en servicios de medio (más parecidos al mandato) o de resultado (semejantes a la compraventa). Este trabajo está enfocado en los servicios de resultado.

\section{B) Los CONTRATOS DE SERVICIOS ENGENDRAN OBLIGACIONES DE HACER}

El objeto del contrato de prestación de servicios es un hecho o un hacer. Es decir, una prestación que consiste en una actividad manual (hacer una obra) o intelectual del proveedor (escribir un libro) con resultados tangibles o intangibles.

El hacer que compromete un servicio podría clasificarse en indelegables o no fungibles y delegables o fungibles. Si habláramos de cosas, tendríamos que decir "fungibles" o "no fungibles", pues esta última categoría también puede aplicarse analógicamente a los hechos debidos. Entre los autores chilenos, algunos ${ }^{19}$ conectan el carácter genérico de la obligación con la fungibilidad de las cosas que, por ser similares entre sí, "tienen el mismo poder liberatorio". En general, las obligaciones genéricas tienen objeto fungible. Pero este razonamiento no suele ponerse en el caso de obligaciones de hacer. En las obligaciones de hacer, el hecho es fungible cuando es delegable en un tercero. Es decir, al acreedor le es indiferente la persona del proveedor y el servicio puede hacerlo un tercero absoluto o delegado por el deudor. El hecho es no fungible cuando es indelegable o su ejecución ha sido contratada en consideración a la persona del deudor. Para los servicios delegables o fungibles resulta indiferente que el hecho lo ejecute el propio deudor u otra persona en lugar suyo.

Los servicios intuitu personae son indelegables o no fungibles, pues se contratan en consideración a la persona del prestador. Hay numerosos argumentos para mantener que su cumplimiento no puede exigirse forzadamente en natura (cf. artículo 1553, reglas $1^{\text {a }}$ y $2^{\mathrm{a}}$ ). El cumplimiento forzado de obligaciones intuitu personae, aunque admisible legalmente, no es viable desde el punto de vista de satisfacción del interés del acreedor, pues el deudor cuyos servicios han sido contratados en atención a su persona no puede cumplir si no quiere cumplir ${ }^{20}$. Por tanto, solo cabe pretender la indemnización de perjuicios por incumplimiento (artículo 1553, regla 3a). Otro aspecto relevante de estos servicios es que se extingue la obligación de prestarlos por muerte del deudor (ex artículo 2163, 5) y por la imposibilidad absoluta sobreviniente para la ejecución (artículo 534 del Código de Procedimiento Civil chileno).

\section{C) Los CONTRATOS DE SERVICIOS SON GENERALMENTE CONTRATOS COMPLEJOS ${ }^{21}$}

Los contratos de prestación de servicios pueden también engendrar obligaciones de dar y de hacer; $y$, en este sentido, son generalmente contratos complejos. El contrato podría

\footnotetext{
19 Cfr. Alessandri et al. (2004) n. 233.

20 Fueyo (1992) p. 279. En el mismo sentido, Abeliuk (2008) n. 805.

21 Cfr. Villanueva (2009b) passim.
} 
llegar a ser una compraventa; por ejemplo, en el supuesto previsto en el artículo 1996, inciso cuarto (cuando el proveedor del servicio proporciona la materia para la confección de la obra). Se lee en el Código Civil chileno que "[p]ueden venderse todas las cosas corporales o incorporales, cuya enajenación no esté prohibida por la ley” (artículo 1810). Por tanto, puede venderse, observa Alessandri ${ }^{22}$, "todo aquello que es susceptible de dominio", también las creaciones del talento y del ingenio (ex artículo 584). Por "cosas incorporales", el Código entiende "derechos", "como los créditos y servidumbres activas" (artículo 565), no "hechos". Esto no impide que el Código califique de mueble el "hecho que se debe", como la ejecución de la obra convenida (artículo 581), una obligación de hacer que en terminología de hoy es claramente la prestación de un servicio. Sin embargo, en la terminología del Código, los hechos no se compran ni se venden; los hechos se prestan; se hacen. En esta línea, mientras los intangibles o cosas inmateriales sean susceptibles de dominio, pueden venderse; y la compraventa de intangibles no es prestación de servicios. En cambio, los hechos son propiamente objeto de prestación de servicios.

\section{D) LOS CONTRATOS DE SERVICIOS SON GENERALMENTE CONTRATOS DE RESULTADO}

Según su objeto, los servicios pueden calificarse también como de medio o de resultado. Los contratos de prestación de servicios engendran obligaciones de hacer; y estas, conforme a una doctrina bastante admitida, pueden ser de medio o de resultado. Las obligaciones de hacer son de medio cuando el proveedor del servicio se obliga a realizar una conducta diligente conforme a los baremos de su profesión u oficio; pero no se obliga a proveer un resultado. Por ejemplo, el médico que se obliga a administrar un tratamiento contra el cáncer. La obligación de hacer y los servicios comprometidos son de resultado, en cambio, cuando el proveedor se obliga a satisfacer un resultado debido. Por ejemplo, el médico que se obliga a realizar un diagnóstico por imágenes ${ }^{23}$.

Si observamos los ejemplos que ofrece el Código Civil chileno y numerosa jurisprudencia, podemos advertir que la mayoría de los contratos de prestación de servicios engendran obligaciones de resultado. Hacer una obra material (como confeccionar una obra o construir un edificio) o inmaterial (como "una composición literaria" o "la corrección tipográfica" de un impreso), según los ejemplos que ofrece el artículo 2006, son servicios de resultado. Los contratos de suministro de gas son servicios de resultado ${ }^{24}$, bien se trate de negocios entre industriales o con consumidores. Lo mismo puede decirse de otros contratos de suministro: electricidad, telecomunicaciones, agua potable y alcantarillado. El taller mecánico se obliga a un resultado cuando presta servicios de reparación de vehículos motorizados (artículos 40 a 43 LPC). La auditoría de un balance es un servicio que compromete un resultado.

Los ejemplos citados revelan claramente la abundancia de servicios de resultado que día a día mueven el tráfico. Esto no quiere decir que no deba reconocerse también la existencia de servicios de medios, como podrían ser algunos tipos de arrendamiento de servicios o el mandato; y la actividad de las profesiones liberales cuando no aseguran un resul-

\footnotetext{
22 Cfr. Alessandri (2003) n. 185.

23 Cfr., en general, Cabanillas (1993); García (2002).

24 En este sentido, Pizarro (2005) passim.
} 
tado (el clásico ejemplo de la defensa de un pleito). En algunos casos, la determinación de la naturaleza del servicio es materia de interpretación del contrato; y exigirá prueba sobre la intención de los contratantes, pues deberá estarse más a ella que a lo literal de las palabras (artículo 1560). Cuando las partes no han reglado la naturaleza de los servicios que contratan, algún autor ${ }^{25}$ propone un elenco de criterios para determinar la naturaleza del hacer: el carácter aleatorio del resultado, el papel activo o pasivo del acreedor en el cumplimiento, la distribución de riesgos en el contrato (si el riesgo pertenece al deudor, la obligación es de resultado; si pertenece al acreedor, la obligación es de medios) e, incluso, la equidad. En otros casos, el contrato se definirá como de medios o resultados según su mismo objeto.

\section{E) LOS CONTRATOS DE SERVICIOS CUANDO ENGENDRAN OBLIGACIONES DE MEDIO}

La distinción entre servicios de medio y de resultado tiene relevancia para la configuración y prueba del incumplimiento. Estudios recientes ${ }^{26}$ coinciden y reafirman la convicción de que la culpa no es una condición necesaria para el despliegue de las consecuencias jurídicas asociadas al incumplimiento. Sin embargo, en las obligaciones de medio o de diligencia, como son los servicios de medio, la culpa se identifica con el incumplimiento. Es decir, la falta de diligencia o cuidado debido (artículo 44) equivale a un incumplimiento.

Por otra parte, conforme demuestra el estudio recién citado $^{27}$, nada agrega a la obligación del deudor el texto del inciso tercero del artículo 1547: "La prueba de la diligencia o cuidado incumbe al que ha debido emplearlo". Frente a la demanda del acreedor, que afirma la existencia de la obligación mediante el contrato en que tiene su fuente y el incumplimiento del deudor (artículo 1698) solo cabe alegar y probar la diligencia o cuidado por parte del deudor que ha debido emplearla en el desarrollo de la prestación. La diligencia o cuidado es también el cumplimiento de la obligación; y, por tanto, su extinción (artículo 1698). Por tanto, no tiene ninguna relevancia la distinción entre servicios de resultado y de medio en lo que se refiere a la carga de la prueba. En ambos casos la prueba de haberse extinguido la obligación por su cumplimiento incumbe al deudor del servicio, sea este de medio o de resultado ${ }^{28}$.

\section{F) LA PRESTACIÓN DE SERVICIOS AL CONSUMIDOR}

En el Derecho clásico la división más relevante de los contratos de servicio parece haber sido en atención a su gratuidad u onerosidad. Los servicios gratuitos se subsumían en la figura del mandato; los servicios remunerados en la figura de las locatio conductio ${ }^{29}$. En el Código Civil chileno el mandato es naturalmente remunerado (2118). Los arrendamientos de obra material e inmaterial también lo son (artículos 1997, 1998, 2006), e incluso el Código reconoce el depósito remunerado como una especial clase de contrato de servicios

\footnotetext{
25 Cfr. Cabanillas (1993) pp. 40-46; en sentido semejante, Peñailillo (2006) p. 226.

26 Cfr. Pizarro (2008) p. 256 y autores citados por él.

27 Pizarro (2008), p. 262.

28 Cfr. también PeÑailillo (2006) p. 228.

29 Cfr. Barros (2010) p. 328, quien se remite a un pasaje de las fuentes romanas (Paulo, D. 17,1,1,4).
} 
(artículo 2219). De manera que la gratuidad u onerosidad del servicio ha dejado de ser relevante. Todos los servicios relevantes en el tráfico jurídico son remunerados.

La distinción más relevante en la actualidad parece ser la que diferencia entre servicios a clientes en general y servicios a consumidores. Todo indica, como se ha expresado anteriormente, que los contratos de prestación de servicios a consumidores, incluidos los que reparación de cualquier bien (artículo $41 \mathrm{LPC}$ ), y los servicios básicos (artículo 25 LPC) tienen el estatuto de responsabilidad por incumplimiento que les confiere la misma ley. En cambio, la responsabilidad por incumplimiento de contratos de prestación de servicios que constituyen acto de comercio queda sujeta al régimen general del Código Civil.

Esta revisión preliminar del marco regulatorio general de los contratos de prestación de servicios nos ofrece una perspectiva para identificar ahora el supuesto de hecho que causa la responsabilidad del deudor: el incumplimiento.

\section{EL INCUMPLIMIENTO COMO PRESUPUESTO DE RESPONSABILIDAD}

La responsabilidad contractual tiene como presupuesto el incumplimiento por parte del deudor de una prestación debida por causa de un contrato. Son igualmente incumplimiento la falta de prestación como también la prestación de calidad defectuosa, que no satisface el estándar del contrato y resulta por esto ser indebida o disconforme con el contrato; y la prestación efectuada tardíamente.

\section{A) El INCUMPLIMIENTO EN GENERAL}

Se enseña ${ }^{30}$ que la prestación es el elemento objetivo de la obligación, lo que se debe, la conducta que se exige al deudor. El objeto de la prestación puede ser, a su vez, un dar, un hacer o un no hacer. Si cumplimiento o pago efectivo es la prestación de lo que se debe (artículo 1568), incumplimiento es la falta de satisfacción de lo debido, sea total o parcialmente, pues el acreedor bajo ningún concepto está obligado a aceptar en cumplimiento una prestación diversa a la que se debe, "ni aun a pretexto de ser de igual o mayor valor" (artículo 1569). Esto concuerda con el artículo 1556 que dispone que el incumplimiento se configura cuando la obligación, es decir, la prestación debida, no se cumple, se cumple imperfectamente o se retarda el cumplimiento. Si conectamos este incumplimiento con el contrato podemos afirmar que lo debido, su cumplimiento y su incumplimiento, viene previsto por la regla contractual. O bien, como se ha expresado, por el programa o propósito práctico del contracto ${ }^{31}$. El contrato establece un estándar conforme al cual debe hacerse la prestación. Toda prestación que no satisface el baremo fijado en el contrato constituye, o puede constituir, incumplimiento.

Lo dicho conecta con las consecuencias que atribuyen al incumplimiento los artículos 1489, 1553, 1555, y 1568. El artículo 1489 discurre sobre el supuesto de "no cumplirse por uno de los contratantes lo pactado" y le atribuye consecuencias. Otro tanto hace el artículo 1553, donde el cumplimiento es la "ejecución del hecho convenido"; es decir, con-

30 Cfr., por todos, Abeliuk (2008) nn. 24-25.

31 Cfr. Vidal (2007), pp. 41-59, quien recibe en Chile a Morales Moreno (1983), Pantaleón Prieto (1993). 
tratado. El incumplimiento se obtiene por la negación de esta proposición: la inejecución del hecho convenido. Y el artículo 1555 donde las consecuencias del incumplimiento se relacionan con "el objeto", es decir, con el fin, "que se tuvo en mira al tiempo de celebrar el contrato": un proyecto, un estándar contratado.

El artículo 1568 define el pago como "la prestación de lo que se debe". El pago como prestación de lo debido es también el cumplimiento de lo debido. Si lo debido tiene por fuente el contrato, el cumplimiento es la prestación de lo debido en el contrato. El incumplimiento, la falta de prestación de lo debido. Por otra parte, de acuerdo a la regla del artículo 1545 también puede afirmarse que el incumplimiento es la infracción de un contrato, pues "todo contrato legalmente celebrado es una ley para los contratantes".

Un aspecto relevante para algunas consencuencias del incumplimiento que no se abordan en este artículo es la imputabilidad de este al deudor. El incumplimiento en sí mismo es un hecho objetivo ${ }^{32}$. Otra cosa es que la imputabilidad de este hecho al deudor tenga sus consecuencias específicas. En algunos casos la falta de diligencia o cuidado configura por sí misma el incumplimiento de la prestación debida (como en las obligaciones de medio). En este trabajo interesa destacar que cualquier desviación de las obligaciones que impone el contrato, con independencia del tipo de obligación de que se trate, y de que la falta de ejecución sea o no imputable al deudor ${ }^{33}$ configura un incumplimiento. Trasladando todo esto al campo de los servicios, el incumplimiento del proveedor se configura entonces: no haciendo el hecho contratado, haciendo imperfectamente el servicio, o haciéndolo tardíamente (cf. artículo 1556).

\section{B) EL “SERVICIO DEFECTUOSO” EN LA LPC}

Para algunos autores, el "servicio defectuoso" es un servicio que ha causado un daño por el incumplimiento de una obligación de seguridad. El servicio defectuoso se equipara a un servicio peligroso o riesgoso; un servicio que por sí mismo tiene la virtualidad de causar daños corporales o morales en las personas ${ }^{34}$. Este servicio defectuoso, entendido como servicio peligroso, es el que regula nuestra LPC en sus artículos 44 a 49 (Título III, Párrafo 5०: "Disposiciones relativas a la seguridad de los productos y servicios"). El proveedor de este tipo de servicios está obligado a informar al usuario de la peligrosidad del servicio (artículo 45); o pedir que la autoridad administrativa o judicial declare esta peligrosidad si se advierte con posterioridad (artículo 46). La LPC atribuye responsabilidad solidaria por los daños causados por estos servicios "riesgosos" en el sentido de "inseguros" al productor, importador y primer distribuidor (artículo 47). El o los demandados pueden eximirse de responsabilidad probando que el servicio cumplía con todas las medidas preventivas y de seguridad que exigen los reglamentos o la ley (artículo 47, inciso $2^{\circ}$ ). El párrafo no exime al proveedor de responsabilidad contractual; y por eso debe cambiar o devolver el precio del producto declarado peligroso (artículo 48). Sin embargo, atribuye responsabilidad a terceros implicados en la provisión del servicio por los daños causados por su inseguridad

\footnotetext{
32 Abeliuk (2008) p. 792.

33 Morales Moreno (2006) (Madrid, 2006), pp. 55-92, 56.

34 Cfr. Villanueva (2009a) pp. 567-635; Ortí et al. (2006) passim.
} 
no informada o no declarada por la autoridad ${ }^{35}$. Las consecuencias dañosas del servicio riesgoso o inseguro son propias de la responsabildiad extracontractual. La responsabilidad por "servicios defectuosos" en este sentido es responsabilidad por productos, Products Liability.

Sin embargo, lo que aquí tratamos no es Products Liability. La LPC utiliza este concepto en otro sentido. El "servicio defectuoso" del artículo 41 LPC es un servicio imperfecto; es decir, un servicio no hecho conforme a lo prometido, un servicio disconforme con lo pactado. Es un cumplimiento imperfecto, un servicio mal hecho, que no tiene la calidad comprometida y esperada por el consumidor. El artículo 41 atribuye responsabilidad por este incumplimiento al proveedor del servicio y las consecuencias del incumplimiento solamente pueden recaer en él, pues estas son: prestar nuevamente el servicio o devolver el precio pagado por él, sin perjuicio del derecho del consumidor a pedir la reparación de los perjuicios sufridos. Además, el consumidor debe acreditar la existencia del contrato, como se lee en la LPC, "mediante la documentación respectiva" (artículo 21, inciso final). Es decir, en el artículo 41 LPC se está haciendo valer una responsabilidad contractual. Abona la interpretación propuesta el texto mismo del artículo 43, que se lee casi a continuación y pertenece al mismo párrafo. El artículo $43 \mathrm{LPC}$ se refiere a las consecuencias del incumplimiento de obligaciones "contractuales" del prestador de un servicio contratado a través de un intermediario. El defecto a que se refiere el artículo 43 está asociado al incumplimiento de obligaciones que el proveedor debía satisfacer por contrato. Nuevamente, es una responsabilidad contractual. Los artículos 40 a 43 pertenecen, por fin, al Párrafo 4 o del Título III de la LPC: "Normas especiales en materia de prestación de servicios". Se advierte claramente la intención del legislador de distinguir el fenómeno de los servicios no hechos conforme a lo pactado de los servicios peligrosos por inseguros, regulados en el párrafo siguiente del mismo título de la LPC.

\section{C) El CUMPLimiento TARDíO}

El cumplimiento tardío es el que se hace después de expirado el plazo que fijaba el contrato para hacerlo. El cumplimiento tardío supone que el incumplimiento no es definitivo y que el acreedor o consumidor aceptó la prestación después del tiempo en que esta era exigible. Este supuesto tiene relevancia para las obligaciones que consisten en pagar una suma de dinero pues el cumplimiento tardío engendra la obligación de pagar intereses (artículo 1559). El cumplimiento tardío de una obligación de hacer podría engendrar la obligación de indemnizar los perjuicios del retardo (artículo 1553pr). Pero estos no están tasados como en el caso del artículo 1559, y exigen la prueba en juicio de su especie y cuantía. El cumplimiento tardío, aceptado por el acreedor, tiene consecuencias difíciles de medir en cuanto a su cuantía.

Examinaremos a continuación las consecuencias jurídicas del incumplimiento de contratos de servicios.

35 En un sentido algo diverso, Cfr. Corral (2006) pp. 104-106. 


\section{LA RESPONSABILIDAD POR INCUMPLIMIENTO DE CONTRATOS DE SERVICIOS}

El centro de este estudio consiste en afirmar que la responsabilidad civil por incumplimiento de contratos de servicios consiste en una serie de sanciones o consecuencias, que incluye la obligación de indemnizar perjuicios, pero que no se limita a ella. El incumplimiento de obligaciones de hacer que engendra un contrato de servicio tiene las siguientes consecuencias. En primer lugar, el prestador del servicio puede ser obligado a hacer de nuevo el servicio. En segundo lugar, puede ser obligado a devolver el precio pagado por el servicio no hecho. Por último, el prestador puede ser obligado a indemnizar los perjuicios causados por el incumplimiento, en la medida en que estos le sean imputables. Estas son las sanciones que se analizan a continuación.

\section{A) La ObligaCión DE HACER DE NUEVO EL SERVICIO}

La obligación de hacer de nuevo el servicio responde a una pretensión de cumplimiento del acreedor insatisfecho. El deudor no ha cumplido y el acreedor pide que se cumpla lo pactado. Esto implica la reiteración de lo hecho. En el plano civil general, esta obligación tiene su fuente en el artículo 2002 del Código Civil:

Si el que encargó la obra alegare no haberse ejecutado debidamente, se nombrarán por las dos partes peritos que decidan.

Siendo fundada la alegación del que encargó la obra, el artífice podrá ser obligado, a elección del que encargó la obra, a hacerla de nuevo o a la indemnización de perjuicios. La restitución de los materiales podrá hacerse con otros de igual calidad o en dinero.

Esta regla está en el párrafo 8 del Título XXVI del Libro IV, sobre los contratos para la confección de una obra material. El artículo 2006, que pertenece al conjunto de normas que el Código Civil agrupa bajo el epígrafe "Del arrendamiento de servicios inmateriales" dispone expresamente que los servicios regulados en dicho párrafo se sujetan a las disposiciones especiales de los artículos 1997 (estas obras se hacen al precio pactado, al que se paga por la misma clase de obras o al regulado por peritos), 1998 (el precio es esencial en este tipo de obras), 1999 (procede indemnización de perjuicios según las reglas generales siempre que no se haya ejecutado lo convenido) y 2002 (el que encargó la obra tiene derecho a pedir que se haga de nuevo si alegare no haberse hecho debidamente).

Bajo el mismo epígrafe, en el artículo 2012, el Código Civil dispone que "los artículos precedentes se aplican a los servicios que según el artículo 2118 se sujetan a las reglas del mandato, en lo que no tuvieren de contrario a ellas". Es decir, los artículos precedentes se aplican a los servicios de "profesiones y carreras que suponen largos estudios, o a que está unida la facultad de representar y obligar a otra persona respecto de terceros" (artículo 2118), como los servicios de médicos y abogados.

Es decir, la posibilidad de pedir que se haga de nuevo el servicio es una pretensión que puede deducirse por el incumplimiento o cumplimiento imperfecto de una gran gama 
de servicios: servicios de confección de obra o contratos de obra o construcción, servicios inmateriales de cualquier tipo y, en lo que sean aplicables, servicios de profesiones que suponen largos estudios. Por ejemplo, en el ámbito del contrato de construcción, la responsabilidad del artículo 18 del D.L. 458, de 1976, Ley General de Urbanismo y Construcciones, se materializa en la subsanación de las fallas o defectos por quien resulte responsable de ellos, haciendo de nuevo, o reparando el defecto. Si esto no es posible, se hacen efectivas las indemnizaciones en dinero. Se trata claramente de la facultad del acreedor de hacer subsistir el contrato e insistir en el cumplimiento de lo pactado; y de la obligación del deudor de garantizar el resultado subsanando el incumplimiento.

Siempre que se pide el cumplimiento de un contrato de servicios, en realidad se está pidiendo al obligado a prestarlo la subsanación del incumplimiento. El demandado podría rechazar la petición si de algún modo es imposible la repetición o si se trata de un servicio personalísimo, indelegable. La pretensión iría, en este último caso, contra la libertad personal. El deudor no quiere hacer de nuevo el servicio. En este caso, el acreedor tendría que optar por otra sanción como la resolución o la indemnización de perjuicios. En los demás casos, la subsanación del incumplimiento haciendo de nuevo el servicio tiene visos de ser una obligación de garantía del deudor.

En el ámbito de servicios a consumidores, el artículo 41 LPC replica esta sanción. El prestador del servicio se hace responsable del servicio o reparación. Es decir, se obliga a la prestación y responder por ella haciéndola de nuevo o indemnizando al consumidor. En consecuencia, el consumidor puede reclamar del desperfecto o daño ocasionado por un servicio defectuoso. Si el tribunal estima procedente el reclamo dispondrá que "se preste nuevamente el servicio" sin costo alguno para el consumidor. Es decir, que se haga de nuevo el servicio, quedando obligado el prestador a subsanar su incumplimiento cumpliendo con su obligación de garantía.

El análisis precedente permitiría concluir que la opción del acreedor por pedir el cumplimiento, si este es posible, se traduce en la posibilidad de exigir al deudor que subsane el incumplimiento o garantice el resultado, haciendo de nuevo el servicio. Y que esta sanción o "remedio" (como sustituir la cosa defectuosa por otra) es uno de los varios mecanismos de protección del sistema de responsabilidad contractual por incumplimiento de contratos de servicios.

\section{B) LA ObligaCión DE DEVOLVER El PRECIO PAGADO POR EL SERVICIO}

La obligación de devolver o restituir el precio pagado es una consecuencia jurídica de la resolución del contrato por incumplimiento. Supone, además, que el acreedor del servicio pagó por él; y que el proveedor no cumplió o cumplió imperfecta o no debidamente lo pactado. En efecto, si el contrato se rescinde por el hecho del incumplimiento (artículo 1489), las prestaciones cumplidas deben restituirse (artículo 1487); y las prestaciones debidas se extinguen (artículo 1567).

Las restituciones debidas por resolución de un contrato de construcción están en parte reguladas en el Código Civil: 
Artículo 1999. Habrá lugar a la indemnización de perjuicios, según las reglas generales de los contratos, siempre que por una o por otra parte no se haya ejecutado lo convenido, o se haya retardado su ejecución.

Por consiguiente, el que encargó la obra, aun en el caso de haberse estipulado un precio único y total por ella, podrá hacerla cesar, reembolsando al artífice todos los costos, y dándole lo que valga el trabajo hecho y lo que hubiere podido ganar en la obra.

Es decir, el contrato termina por incumplimiento, pero sin efecto retroactivo. El que encargó la obra debe abonar el costo de los materiales ya adheridos al edificio u obra, el trabajo hecho y lo que el artífice "hubiere podido ganar en la obra". Aunque debería entenderse que proporcionalmente a lo hecho; y no a lo por hacer.

Si corresponde restituir materiales, el artículo 2002 agrega que estas restituciones pueden hacerse con otros de igual calidad o por su valor en dinero.

Hasta ahora hablamos de restituciones por resolución de un contrato de obra. Pero cómo deben hacerse las restituciones en contratos de servicio inmateriales. En realidad, parece que, en estos casos, no son posibles las restituciones. Aunque esto no significa que no sea posible la resolución. El contrato se resuelve ex nunc; y proceden las indemnizaciones en las que se estime el daño causado por el incumplimiento. Pero no podrían hacerse restituciones.

El problema de las restituciones que se siguen a la resolución de un contrato de prestación de servicios me parece bien ilustrado en el caso resuelto en sede de casación por la Corte Suprema como Opazo con Inmunomédica (2010). El demandante pretende la indemnización del daño moral por el incumplimiento de un contrato de prestación de servicios de diagnóstico médico mediante exámenes de sangre (protrombina o velocidad de sedimentación en la sangre); exámenes que resultaban urgentes para una intervención quirúrgica que había que hacerle a su hijo. El examen se hizo y salió alterado, por lo que fue necesario postergar la operación. Esto causó gran aflicción en el menor y su familia. Se reiteró el mismo examen al joven en otro lugar, donde salió normal; por lo que el padre alega infracción al contrato. A petición del mismo demandante, el Servicio de Salud Regional levantó un sumario sanitario contra el Laboratorio, el que posteriormente se sobreseyó por ser imposible acreditar la responsabilidad del laboratorio atendida la circunstancia "de ser muy sensibles las muestras y el uso de reactivos [por lo que] no [se] pudieron comparar" con los resultados de otros exámenes. (La resolución sanitaria hace peso en la decisión del juicio pues impide que quede acreditado el incumplimiento que invoca el demandante.) En primera instancia el demandante obtiene la indemnización de daño moral que el juez de letras regula discrecionalmente en la suma de \$15.000.000 contra el demandado. La Corte de Apelaciones de Concepción revoca. La Corte Suprema rechaza los recursos de casación en la forma y en el fondo deducidos contra esta última sentencia que, por tanto, decide el juicio a favor del demandado.

Desde luego, por su naturaleza, el contrato de prestación de servicios no podría resolverse por incumplimiento. "[N]o se divisa cómo podrían volver las cosas [al] estado anterior, atendida la naturaleza de la prestación de servicios" (Considerando 7 del fallo de segunda instancia). "[H]abiéndose fundado la demanda en el citado artículo 1489 del Có- 
digo Civil, solicitando la resolución de contrato, no puede el tribunal dar lugar a la demanda de indemnización de perjuicios, por vía principal, por estar imposibilitado de resolver un contrato de la naturaleza jurídica consignada, y por ende, siendo esta indemnización accesoria a la resolución, no subsiste independientemente la indemnización de perjuicios" (Considerando 10); "no se puede alterar el objeto principal del pleito, o más precisamente modificar la identidad de la causa de pedir" (Considerando 11).

Sin entrar por ahora en el problema del carácter accesorio que se atribuye a los perjuicios solicitados, cuestión a la que la Sala Primera dedica parte de su fallo, se discute si puede resolverse un contrato sin que se ordene, a la vez, hacer restituciones para volver las cosas al estado anterior. La Corte de Concepción se inclina por una respuesta negativa a esta cuestión, criterio al que se adhiere la Corte Suprema al rechazar el recurso de casación en el fondo. Sin embargo, todo indica que es perfectamente posible resolver un contrato sin que proceda hacer restituciones. La resolución opera ex nunc, y no ex tunc, por no ser posible restituir hechos ni el costo asociado a estos. Este es el razonamiento subyacente al artículo 1999 y 2002. El valor de lo hecho no puede restituirse, como puede deducirse de la regla del artículo 1999.

Opazo con Inmunomédica (2010) no se discutió en sede de consumo; pero el contrato que se reputa no cumplido está sujeto, a juicio de este estudio, a la LPC. El demandante podría haber deducido un reclamo ante el Juzgado de Policía Local competente; y exigido alguna de las sanciones previstas en el artículo 41 LPC: reiteración del servicio, devolución del precio y, siempre, indemnización de perjuicios. Ahora bien, nuevamente, la devolución del precio es una restitución por causa de resolución. Pero el servicio hecho tiene un valor que no puede restituirse si no puede, a su vez, deshacerse el hecho. De manera que en este caso la devolución del precio no habría sido procedente tampoco.

Adquiere relevancia y justificación por sí misma la indemnización de perjuicios, cuestión a la que nos referimos a continuación.

\section{C) LA OBLIGACIÓN DE INDEMNIZAR PERJUICIOS}

\section{1) Distinguir entre servicios a consumidores y otros contratos de servicios}

La indemnización de perjuicios es una sanción especialmente relevante para el acreedor de unos servicios frustrado por el incumplimiento. En este ámbito, vuelve a adquirir relevancia el régimen aplicable al servicio no cumplido. Los daños y perjuicios por servicios en que no es parte un consumidor quedan sujetos al régimen supletorio general del Código Civil. En cambio, si el acreedor es un consumidor, este puede pedir directamente esta sanción por aplicación de los artículos $3^{\circ}$, letra e) y 41 LPC. En este campo los consumidores tienen muchas ventajas en comparación con otros acreedores. A continuación se analiza el problema de la pretensión indemnizatoria del acreedor civil o mercantil; y luego la del consumidor.

Para el acreedor civil o mercantil (un cliente cualquiera que no es consumidor) el problema dogmático consiste en la radicalidad de la opción que exige el artículo 1489 del Código Civil chileno para el caso del incumplimiento de un contrato de servicios. Según esta regla, el acreedor tiene derecho a pedir "o la resolución o el cumplimiento del contrato, 
con indemnización de perjuicios"; de donde se deduce que solo podría pedir la indemnización de perjuicios como pretensión accesoria a una de las dos anteriores.

Esto conecta con la discusión de cómo pedir los perjuicios por incumplimiento de contrato. Hay un sector de la doctrina nacional que sostiene que en los contratos bilaterales el incumplimiento obliga al acreedor a sujetarse a la opción que le ofrece el artículo 1489 del Código Civil. O incluso, que prevalece la obligación de exigir el cumplimiento en naturaleza ${ }^{36}$. Alessandri habría sido partidario de la obligación de pedir el cumplimiento forzado y solamente agotada esta opción, la indemnización de perjuicios; aunque Somarriva opinaba que frente a la mora del deudor, el artículo 1537 expresa un principio, no una excepción, y faculta al acreedor a pedir el cumplimiento forzado (la obligación principal) o la pena, aun en el caso de obligaciones de dar ${ }^{37}$. La doctrina chilena ha seguido una u otra postura, aunque con apoyo dogmático en diversas reglas ${ }^{38}$.

Más recientemente, parece imponerse la autoridad de autores como Peñailillo ${ }^{39}$ que sugieren que podría pedirse directamente la indemnización de perjuicios, "lo cual implica resolver la obligación" ${ }^{40}$. Aunque matiza: "Si siendo de hacer [la obligación, ésta] proviene de contrato (bilateral), el acreedor puede pedir la resolución del contrato conforme al artículo 1489 y, con ese texto y el artículo 1553, 3º, podrá pedir indemnización; y aún sin el artículo 1489 podrá pedir directamente indemnización, solo que al no acudir al artículo 1489 solo quedará sin efecto esa obligación” ${ }^{41}$. Para defender la opción del acreedor a la indemnización de perjuicios como pretensión principal, otros autores apelan al principio de la reparación integral del daño ${ }^{42}$.

Aplicar estas normas a los contratos de servicios (que engendran obligaciones de hacer) es algo más complejo de lo que parece. Frente al incumplimiento, el acreedor difícilmente seguirá interesado en exigir el cumplimiento, que consiste en un hecho que el deudor no hizo, no hizo bien, no puede o no quiere hacer. Por otra parte, el acreedor no siempre tendrá interés por la resolución del contrato. En efecto, el hecho debido (mal hecho) generalmente no puede deshacerse; es decir, no es posible efectuar restituciones 'de hacer' en contrapartida a la restitución del precio. Esto conduce a pensar que el verdadero interés del acreedor de obligaciones de hacer no cumplidas es la indemnización de los perjuicios causados por el incumplimiento. La indemnización de perjuicios permite al acreedor recuperar el valor de la prestación (daño intrínseco) y otras pérdidas sufridas a causa del incumplimiento (daño extrínseco). En estas últimas pueden recuperarse, por ejemplo, los costos de reparación de una prestación defectuosa, los gastos de preparación de la prestación, o los gastos causados directamente por el incumplimiento (honorarios de abogados, notificaciones judiciales o notariales) $)^{43}$.

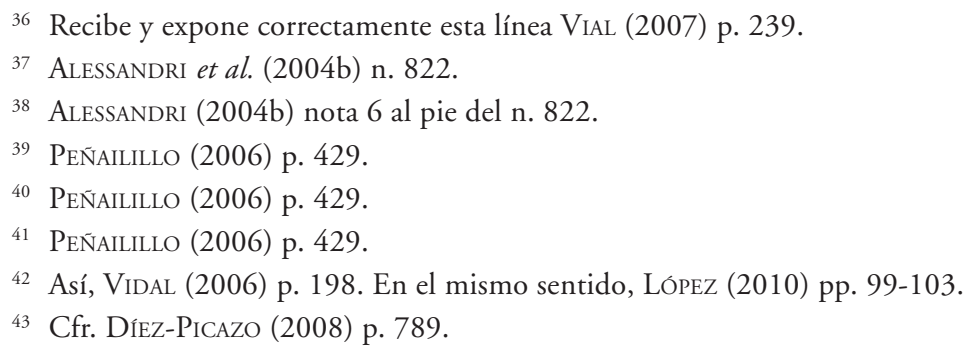




\section{2) Autonomia de la pretensión indemnizatoria. Una revisión de la casuistica}

Se afirma que conforme al estado actual del Derecho civil chileno, el acreedor no podría pedir directamente la indemnización por vía del artículo 1553 , número $3^{\circ}$, sin pedir la resolución por vía del artículo 1489; pues no podría concederse una indemnización de perjuicios por el incumplimiento de un contrato que sigue vigente y obliga a las partes ${ }^{44}$. La casuística de tribunales superiores ilustra este problema pero no lo resuelve. Reproduce en cierta forma la perplejidad de los autores. Esto se aprecia en dos casos recientemente fallados por la Corte Suprema de Justicia que son los que se presentan a continuación.

El primero estos casos es Opazo con Inmunomédica Laboratorio (2010), ya tratado más arriba. El otro es Inmobiliaria e Inversiones con Salazar Berrocal y otra (2010). En ambos se aprecia la importancia que tiene para el acreedor la indemnización de perjuicios, la dificultad para plantear correctamente el litigio desde un punto de vista dogmático y, a la vez, la perplejidad del juzgador.

En Opazo (2010) la indemnización de perjuicios que solicita el demandante (daño moral) se pide como accesoria a una pretensión principal: la resolución del contrato por incumplimiento, según el artículo 1489 del Código Civil. La judicatura no ha podido acceder a la demanda por no estar acreditado el incumplimiento del contrato. Pero el supuesto se presta para discusiones en torno a la naturaleza de la indemnización que se pide. Esta es una primera vacilación del juzgador. Parece que al demandante le interesa una indemnización de daños consecuenciales, que no consisten en el valor de la prestación. Aunque previsibles (y por tanto indemnizables) atendida la naturaleza del contrato de prestación de servicios de diagnóstico médico, los perjuicios que pide (el daño moral o de aflicción) no consisten en lo que el demandado debería restituir de resolverse el contrato. La argumentación del tribunal queda entrampada en el problema de la naturaleza de la indemnización; pues todo indica que el tribunal razona sobre la base de una indemnización que debería cumplir una función restitutoria. Sin embargo, el demandante ha pedido indemnización del daño moral, que es un daño consecuencial, y no una restitución por causa de resolución del contrato.

El otro asunto que produce perplejidad es el problema de la supuesta accesoriedad que se atribuye a la indemnización cuando esta se funda en el artículo 1489. Efectivamente. Si los daños que se piden son consecuenciales y no cumplen una función restitutoria del valor de la prestación, tal vez no podría discutirse el carácter accesorio de esta pretensión. La Primera Sala, sin embargo, se inclina por favorecer la autonomía de la pretensión; lo que, implícitamente, supone reconocer su función a la vez restitutoria e indemnizatoria de daños consecuenciales. En todo caso, me parece que de admitirse la autonomía de la indemnización de perjuicios, la pretensión debería incluir el valor de la prestación y otros daños que sean objetivamente imputables al deudor; es decir, daños previsibles al tiempo del contrato y que sean "resultantes" (artículo 1553, 30) de la infracción (requisito de causalidad $)^{45}$.

44 Pienso que recapitula por todos, Peñailillo (2006) p. 429.

45 Cfr. Corral (2010) p. 155. 
El segundo caso es Inmobiliaria con Salazar Berrocal (2010). En este caso la parte demandante pide el cumplimiento de un contrato de prestación de servicios con indemnización de perjuicios (pena) y, en subsidio, la terminación del contrato con indemnización invocando como causa de pedir el artículo 1489 del Código Civil chileno.

Las empresas demandadas se habían obligado a realizar el loteo de una propiedad rural en parcelas de 5.000 metros cuadrados, asumiendo ellas todas las obligaciones correspondientes, como apertura y ripiado de calles, señalamiento de deslindes, promoción y venta de 40 de los 42 lotes en que tenía que subdividirse el predio, instalación de luz eléctrica y de agua potable. La demandante alega que las demandadas no cumplieron con la obligación de instalar el agua potable en dos sentidos: $1^{\circ}$, por extemporáneo ingreso ante la autoridad administrativa de la solicitud de instalación y funcionamiento del sistema; 20, por graves deficiencias de construcción y funcionamiento; hechos que el Juez de Letras estima acreditados por diversos medios de prueba. En consecuencia, se acoge la demanda.

El juez de letras condena a la parte demandada a pagar $\$ 7.504 .378$, suma a que ascienden los gastos en que ha debido incurrir la demandante para reparar las deficiencias del sistema instalado; más la suma de $\$ 25.000 .000$ como indemnización de perjuicios avaluados anticipadamente por las partes en el contrato a través de una cláusula penal. Es decir, condena al cumplimiento (por equivalencia) más la pena. Esta condena infringe lo dispuesto por el artículo 1537, que dice que una vez constituido el deudor en mora, no puede el acreedor pedir el cumplimiento de la obligación principal y la pena; sino una u otra. Una Sala de la Corte de Apelaciones de Temuco revoca en cuanto a la pena (indemnización) y confirma en cuanto a lo demás. La Primera Sala de la Corte Suprema acoge un recurso de casación en la forma por decisiones contradictorias.

En efecto, el demandado no puede ser condenado al cumplimiento y la pena, decisión que infringe el artículo 1537. La sentencia de reemplazo, entonces, acoge la demanda de indemnización de perjuicios por incumplimiento, condenando a las empresas demandadas a pagar $\$ 25.000 .000$ como suma “única y total” en que las partes han avaluado anticipadamente los perjuicios. Es decir, la sentencia de reemplazo condena a pagar la pena establecida por las partes para el caso de incumplimiento. La ratio que decide el juicio a favor de la indemnización es el incumplimiento del deudor, que otorga al acreedor el derecho a pedir el cumplimiento forzado o la indemnización de los perjuicios causados. La pena pactada en una cláusula penal se interpreta como una petición principal o autónoma, que consiste en perjuicios avaluados anticipadamente por las partes en una suma única y total. Se condena implícitamente conforme a la regla del artículo 1537 del Código Civil.

En Inmobiliaria (2010) el demandante pide perjuicios como pretensión accesoria a una de cumplimiento, según el artículo 1489 del Código Civil. Obtiene perjuicios por incumplimiento de contrato, según ellos fueron avaluados anticipada y convencionalmente en una suma única y total por las partes. "En consecuencia, razona la Sala, al haber existido un incumplimiento contractual, debe aplicarse como suma única y total que resarcirá los perjuicios sufridos por la actora, aquella que las partes libremente convinieron de forma anticipada y que se contiene en la cláusula décima del contrato[...]". Podemos decir que aunque la demandante pide conforme al artículo 1489, implícitamente el Tribunal condena según el criterio del artículo 1553, número $3^{\circ}$ del Código Civil; es decir, condena a 
indemnizar los perjuicios resultantes de la infracción del contrato de prestación de servicios (que las partes denominaron "convenio y mandato") mediante una suma única y total, que es compensatoria de todos los daños. Se pide mal; pero el Tribunal corrige mediante una condena adecuada a la naturaleza de las obligaciones infringidas.

Tanto en Opazo (2010) como en Inmobiliaria (2010) vemos cómo los errores en la causa de pedir arriesgan la condena que piden los demandantes. Puede afirmarse que en ambos casos los demandantes pretendían la indemnización de perjuicios resultantes de la infracción de un contrato que engendraba obligaciones de hacer. Sin embargo, en ambos casos invocan el artículo 1489 como causa de pedir. Es decir, piden una indemnización como accesorio de una condena principal (resolución o cumplimiento). Opazo pide resolución con indemnización de perjuicios; Inmobiliaria pide cumplimiento con indemnización de perjuicios. Opazo no obtiene por ser imposible la resolución de un contrato de prestación de servicios (según el razonamiento de la Corte de Apelaciones de Concepción) y la indemnización, algo accesorio a la resolución. Inmobiliaria obtiene por haberse establecido el incumplimiento. Esta constatación apunta a la centralidad de la prueba del incumplimiento como presupuesto de cualquier pretensión que levante el demandante.

En ambos casos constatamos también que ni la resolución del contrato por incumplimiento (Opazo) ni el cumplimiento forzado (Inmobiliaria) satisface el interés del demandante. En Opazo (2010) el mismo tribunal de alzada lo ve incompatible con la naturaleza del contrato. La resolución de un contrato de servicios no cumplido solo podría engendrar la obligación de restituir el precio pagado por él; sin que el acreedor pueda restituir el servicio o el hecho comprometido y no cumplido, o cumplido imperfectamente (artículo 1556; cf. artículo 1999). No puede haber restituciones recíprocas, en la mayor parte de los casos. La resolución, si se concede, no tiene efecto retroactivo sino de terminación de un contrato por incumplimiento.

En otras palabras, parece irrelevante una condena a restituir. Esto no interesa al demandante. Por otro lado, el cumplimiento forzado tampoco parece demasiado interesante para el acreedor, cuando el deudor ya ha demostrado mediante el incumplimiento o el cumplimiento imperfecto su desinterés o incapacidad. Lo que interesa realmente al acreedor, en la generalidad de los casos, es la indemnización de perjuicios. Es decir, la indemnización compensatoria; lo que le habría significado al demandante (acreedor) el cumplimiento del contrato. (Aunque en Opazo incluso podría afirmarse que se pretenden daños no patrimoniales consecuenciales al incumplimiento.) En Inmobiliaria (2010) las partes habían avaluado anticipadamente la cuantía de este interés mediante una cláusula penal, por lo que no era necesario cuantificar la condena. (Por otra parte, el artículo 1537 impedía al acreedor exigir la obligación principal y la pena.)

La práctica forense está reflejada en estas sentencias. Los abogados piden conforme al artículo 1489 aunque implícitamente pretendan indemnización de perjuicios como cosa principal. Los jueces son reticentes a conceder indemnizaciones fuera del marco del artículo 1489, lugar donde esta cumple una función accesoria. No he encontrado sentencias en que el acreedor pida directamente la indemnización de perjuicios por infracción de un contrato que engendra obligaciones de hacer, como el de prestación de servicios; aunque es evidente 
que en Inmobiliaria (2010) el demandante podía pedir directamente la pena, invocando el artículo 1537 como causa de pedir.

D) La responsabilidad del intermediario de SERVICIOS AL CONSUMidor. EL ARTÍ́CULO 43 LPC

El artículo 43 LPC ofrece un interesante caso de responsabilidad directa del intermediario de servicios al consumidor por incumplimientos imputables al prestador del servicio, con quien el intermediario tiene relaciones de agencia o mandato. Hay una larga lista de sentencias en este campo por responsabilidad de agencias de turismo o de viajes; y alguna contra intermediarios de contratos de seguros. A continuación se ofrece un análisis de este grupo de casos. Esta introducción permite formular algunas reflexiones sobre la naturaleza de la obligación del intermediario como deudor principal en su relación con el consumidor.

\section{1) Casuistica judicial resistente a demandas de indemnización civil}

Un primer grupo de casos está vinculado a la intermediación de servicios de turismo y viajes combinados ${ }^{46}$. Uno de estos intermediarios es Tije Chile S.A., una empresa especializada en viajes de estudio y trabajo en el exterior para estudiantes. En 2006 esta empresa vendió pasajes aéreos de Air Madrid, de ida y vuelta a España, a diversas personas. Los viajes de regreso a Chile de varios de estos pasajeros quedaron sin cumplirse por quiebra de la aerolínea. Esto los obligó a contratar el viaje de regreso a Chile en otro transporte, con los consiguientes costos y molestias no previstos. Varios de estos clientes llevaron sus reclamos a la justicia, que resolvió en unos casos condenando al intermediario, es decir, a Tije Chile, al pago de multas a beneficio fiscal pero absolviéndolo en cuando a la responsabilidad civil. En otros casos, aplicando a mi juicio correctamente el artículo 43 LPC, los afectados pudieron obtener reparación de los perjuicios causados por los incumplimientos imputables al proveedor del servicio.

A continuación examino cuál es el razonamiento para desestimar la pretensión indemnizatoria del consumidor afectado. Lo podemos ilustrar con Grunwald con Agencia de Viajes Tije Chile S.A. (2008). Para configurar la responsabilidad infraccional del demandado, el tribunal aduce la doble relación que tiene el demandado con el demandante: proveedor e intermediario. En cuanto proveedor, el demandado se obligó a prestar asesoría para la realización de un viaje; en cuanto intermediario, contrató el transporte aéreo a nombre y por cuenta de un tercero (Air Madrid). El incumplimiento de Air Madrid pone igualmente al demandado en situación de incumplimiento, en virtud de los artículos 12 y 23 LPC; pero, además, lo obliga a responder directamente al consumidor, según el artículo 43 LPC. En virtud de estas consideraciones, la Corte de Apelaciones de Santiago acoge la demanda en cuanto condena al demandado al pago de una multa a beneficio fiscal; pero mantiene la desestimatoria en cuanto a la reclamación de perjuicios patrimoniales y morales que reclama el afectado. Estos han sido desestimados por el juez de policía local porque considera que la ley $\mathrm{N}^{\circ} 19.496$, de 1997, está diseñada "en torno a la infracción como requisito previo y concomitante al incumplimiento contractual" por lo que "no existe acción reparatoria

46 Cfr. la abundante jurisprudencia citada por Contardo GonZÁlez (2010) pp. 161-164. 
sin infracción que la sustente"; en otras palabras, "no existe indemnización de daños sin infracción”. Anteriormente, en Urra con Tije Chile S.A. (2007) el Juez de Policía Local de Providencia había desestimado la acción del Sernac por considerar que el incumplimiento del proveedor (Air Madrid) no podía imputarse al intermediario. Es decir, en esta línea de razonamiento, las pretensiones de los afectados se ven frustradas; y su única opción para obtener reparación es demandar a la quiebra de la línea aérea, en el extranjero, en un juicio de lato conocimiento para que se determinen los perjuicios.

Para ilustrar cuán arraigada está la idea de que se requiere una previa condena infraccional para configurar cualquier responsabilidad civil en el ámbito de protección del consumidor es que les presento otro caso, contemporáneo con los anteriores: Romeo Viajes Limitada (2007). En este caso la Corte de Valparaíso también absuelve al demandado, que es intermediario de servicios de transporte, de la condena a indemnizar el daño moral causado al demandante por un incumplimiento imputable al proveedor del servicio. El tribunal considera que para que se configure la responsabilidad del intermediario según el artículo 43 de la LPC debe establecerse previamente la responsabilidad infraccional del proveedor del servicio. Esta especie de "solidaridad" del intermediario, afirman los sentenciadores, solo puede hacerse efectiva si se acredita la infracción del proveedor del servicio, a semejanza de lo que ocurre con la responsabilidad del dueño de un vehículo motorizado bajo el artículo 174 de la Ley del tránsito, que solo resulta obligado si el conductor causó los daños mediante infracciones a los preceptos del tránsito.

Afortunadamente, hay otra línea en este mismo grupo de casos. Por ejemplo, Pacheco con Tije Chile S.A. (2008). En Pacheco la Corte de Apelaciones de Santiago califica correctamente la función jurídica de la agencia en el negocio como proveedora directa de servicios de asesoría en la realización de un viaje, e intermediaria en la venta de pasajes. La condena al pago de multas se apoya en la infracción por la agencia de sus propias obligaciones que son, a la vez, infracciones de ley en consideración a los artículos 12 y 23 de la LPC. Sin embargo, la demandada también es condenada al pago de los daños patrimoniales que sufre el afectado por el incumplimiento imputable a la línea aérea. "El eventual incumplimiento de la empresa encargada de efectuar el transporte no es un riesgo que asuma el consumidor, afirma el Tribunal, como sucedería si hubiera contratado directamente con ella, pues de acuerdo [al artículo 43] -que altera la regla general aplicable al simple mandato o comisión- la agencia de viajes está obligada a responder del servicio que como proveedora ha ofrecido al consumidor aun cuando el tercero que debía ejecutarlo no lo cumpla”. Se avalúan los daños del consumidor en el equivalente al monto del pasaje de regreso que tuvo que adquirir para regresar a Chile en otra línea aérea; pero se desestima la demanda en cuanto al daño moral que consiste en las molestias causadas por incumplimiento de la línea aérea. El razonamiento es casi perfecto, si no fuera por la supuesta obligación de configurar una infracción de ley contra el demandado para dictar una condena a indemnizar perjuicios civiles.

La doctrina que tiende a acoger demandas civiles por incumplimiento de obligaciones del proveedor de unos servicios que han sido adquiridos por el consumidor por la intermediación de un agente ya circulaba desde antes en los juzgados de policía local, pero no totalmente establecida. En Hübner con Agencia Eurotour Ltda. (1998) el Tercer Juzgado 
de Policía Local de Santiago condena al intermediario a indemnizar daños patrimoniales y morales causados al consumidor y su familia, que es toda parte en la relación contractual con el intermediario, por diversos incumplimientos imputables a proveedores de servicios de turismo en Brasil. Por lo que se deduce del fallo hecho público por el Sernac, no hay condena infraccional al demandado. En Karina Valenzuela con Turismo Cocha S.A. (2007) la Corte de Apelaciones de Santiago revoca la condena del juez a quo a pagar multas por infracción de ley, pero confirma la condena a indemnizar daños. Se trata de perjuicios por incumplimientos imputables al proveedor de un servicio de transporte contratado por la intermediación de la demandada. "[S]ería contrario a todo sistema de atribución de responsabilidad [sancionar infraccionalmente al intermediario] por un hecho imputable a un tercero", razona el tribunal en un fallo redactado por el abogado integrante señor Emilio Pfeffer Urquiaga. Se confirma la condena a indemnizar perjuicios civiles por daño "material", avaluado en 30.740 pesos, y por daño moral, reducidos por la Sala a la suma de 100.000 pesos.

Pertenece a esta tendencia otro caso, bien resuelto, por la Corte de Apelaciones de Valparaíso. En Mejías con Turismo Zahr (2008), la Corte confirma una sentencia que condena al demandado a indemnizar perjuicios al consumidor por incumplimientos imputables a diversos proveedores de servicios de turismo; pero también confirma la sentencia que rechaza la querella infraccional contra el mismo intermediario, por haberse estimado que las infracciones alegadas no le son imputables.

\section{2) El intermediario como deudor principal en las relaciones con el consumidor}

El análisis anterior permite ahora examinar la función del intermediario en la relación jurídica que se establece entre el proveedor del servicio y el consumidor, la naturaleza de su responsabilidad y de la pretensión resarcitoria del consumidor, y los fundamentos que la explican, desde el punto de vista del sistema del Derecho de protección de los consumidores en contraposición con el derecho común civil y mercantil.

Tal como acertadamente considera la ministra redactora del fallo en Pacheco con Tije Chile (2008) el intermediario es parte en una comisión mercantil que se establece entre un comitente, que es la o las empresas proveedoras de servicios, y el cliente o consumidor que adquiere estos servicios por la intermediación del agente. El intermediario no es parte en el contrato que se perfecciona entre el comitente y su cliente (el consumidor). Es decir, en los casos que hemos visto, Tije no es parte en el contrato de transporte aéreo entre Air Madrid y el pasajero chileno, cliente de la agencia, consumidor del servicio. Sin embargo, Tije es comisionista tanto del consumidor como del proveedor. Es decir, entre el consumidor de los servicios y el intermediario hay también un contrato. En los ejemplos que hemos puesto, este contrato puede ser también un contrato atípico de prestación de servicios de organización de un itinerario de viaje $\mathrm{e}^{47}$. Este contrato se agrega al de mera intermediación o comisión mercantil entre el proveedor del servicio y el intermediario. La comisión mercantil, como sabemos, es un mandato para la realización de actos de comercio (artículos 233 y siguientes del Código de Comercio).

47 Contardo González (2010) passim. 
Si el intermediario es una empresa de mayor envergadura, puede proveer por sí mismo los servicios de transporte combinado, subcontratando con terceros el transporte por tierra, por aire o por mar, los servicios de hospedaje, etcétera. En este supuesto, el intermediario deja de ser tal y adquiere la calidad de contraparte del consumidor, respondiendo directamente frente a él por los incumplimientos en que pueda incurrir, por sí o por sus subcontratistas o dependientes. El caso es distinto y se rige por el artículo 41 LPC, norma que regula una garantía legal de servicios al consumidor, según se ha expuesto más arriba.

Podemos decir que este fue el caso en Carmen Roig con Empresa Corredora de Seguros Andueza y Cía. Ltda. (2004). La demandada no renovó la póliza de un seguro de daños contratado por la demandante, a consecuencia de lo cual la empresa aseguradora no le dio la cobertura de un siniestro, por cuyo costo la demandante pide que se condene a la intermediaria. El juez de policía local hace lugar a la demanda. La Corte de Apelaciones confirma, con costas y declaración de que la suma en que queda condenada la demandada se reduce a los costos del siniestro. Este fallo invoca como fundamento el artículo 43 LPC. Sin embargo el incumplimiento contractual no es imputable al proveedor del servicio (la compañía de seguros) sino al intermediario (la corredora), que no renovó la póliza oportunamente como era su obligación. La condena se fundamenta, en realidad, en un incumplimiento de contrato imputable a la intermediaria; y la condena debería haber tenido por fundamento los artículos $3^{\circ}$ letra e) o el artículo 41 LPC.

Veamos ahora en qué consiste la responsabilidad del intermediario según el artículo 43. Es del todo evidente que esta responsabilidad no es "infraccional"; ni tampoco extracontractual $^{48}$. En efecto, el incumplimiento por el que responde no puede serle imputable como infracción de ley. Observamos esta doctrina, que parece ser la correcta, en Romeo Viajes (2007) y en Mejías con Turismo Zahr (2008), que se resuelven contra la fuerte carga de la tradición de los juzgados de policía local en materia de protección del consumidor, que postula que no hay responsabilidad civil sin responsabilidad infraccional.

Esta posición nos reenvía al ámbito al que pertenece la responsabilidad del intermediario: el ámbito contractual. El intermediario responde por incumplimientos de contrato, incumplimientos suyos y/o de sus comitentes o mandantes. Nos encontramos, por tanto, en presencia de un contrato con el consumidor y de uno o más incumplimientos, ambos presupuestos absolutos de la responsabilidad contractual.

La explicación de la función del artículo 43 LPC podría encontrarse en una norma como el artículo 2152 del Código Civil ${ }^{49}$. Según el artículo 2152, el mandatario puede por un pacto especial tomar sobre su responsabilidad la solvencia de los deudores y todas las incertidumbres y embarazos del cobro. Constituyese entonces principal deudor para con el mandante, y son de su cuenta hasta los casos fortuitos y la fuerza mayor. Lo mismo dispone el Código de Comercio para los comisionistas mercantiles y para los corredores de efectos públicos (artículos 317 a contrario y artículo 67 del Código de Comercio).

48 En otro sentido, pero con conclusiones semejantes, CONTARdo GONZÁlez (2010) pp. 82-98.

49 Este artículo aparece solamente en el Proyecto Inédito, artículo 2303 g, redacción definitiva. 
Según Troplong ${ }^{50}$, a quien Bello cita como fuente en nota al artículo 2303 g. del Proyecto Inédito, por una determinada prima, el pacto constituye al mandatario en un agente del credere. El agente del credere es deudor personal y principal frente al mandante, asegurador de todo hecho y caso fortuito por el que la obligación principal no sea cumplida. A pesar de ser una convención accesoria, este pacto, asegura Troplong ${ }^{51}$, no es necesario que sea expreso. Puede resultar del uso o de las circunstancias. El pacto del credere es un pacto de garantía más fuerte que la fianza porque el mandatario se constituye en deudor principal frente al mandante "y son de su cuenta hasta los casos fortuitos y la fuerza mayor”, como expresa el artículo 2152 del Código Civil. La fianza obligaría al mandante a agotar las acciones contra el deudor principal antes de dirigirse contra el mandatario. En cambio, si hay pacto del credere, el mandante puede dirigirse directamente contra el mandatario. En cuanto asegurador, el mandatario que paga se subroga en las acciones del mandante contra el deudor principal (ex artículo 553 del Código de Comercio). Es decir, conforme al derecho común, el intermediario puede obligarse por convención, como "principal deudor", a responder del cumplimiento de las obligaciones que asumen sus clientes, sean estos el comitente o el consumidor.

Volviendo al Derecho del consumo, podría afirmarse que el supuesto del artículo $43 \mathrm{LPC}$ es el de un intermediario (un comisionista) que responde directamente al consumidor por los incumplimientos imputables al proveedor de servicios contratados por su intermediación. Aplicando las categorías examinadas anteriormente, podríamos afirmar que el intermediario es, por el solo ministerio de la ley, un agente del credere; es decir, un intermediario que es garante de las obligaciones que asume el proveedor de los servicios que se comercializan por su intermediación (comitente frente al intermediario; proveedor frente al consumidor). La responsabilidad del intermediario es una responsabilidad de garantía; sin embargo, por tratarse de obligaciones que consisten en un hacer, parece evidente que el intermediario no puede responder de las obligaciones del proveedor en naturaleza. Su obligación debe ser pagar al consumidor el costo del reemplazo.

El contrato de servicios engendra obligaciones de hacer cuyo cumplimiento forzado es difícil y, en muchos casos, imposible, especialmente si se trata de un hacer indelegable. Sin embargo, si el servicio es delegable el obligado puede satisfacer el interés del acreedor por un tercero. Volviendo al caso de las agencias de viaje: el pasajero no puede obligar a Air Madrid a cumplir con el contrato de transporte cuando la aerolínea ha suspendido operaciones y se encuentra en procedimiento de quiebra. ¿Qué le queda? Exigir al proveedor el cumplimiento por equivalencia; es decir, con un pasaje en otra línea aérea.

Si el proveedor es remiso en el cumplimiento de esta obligación, el consumidor puede exigir al intermediario satisfacer la obligación por un tercero; por ejemplo, proveyendo al consumidor de un pasaje de regreso en otra línea aérea. Si no cumple, está obligado a satisfacer los costos que este incumplimiento cause al consumidor. En el ejemplo, el valor del pasaje de regreso y otros gastos en que el consumidor pudo haber incurrido por causa del incumplimiento imputable al proveedor (daño emergente y lucro cesante).

\footnotetext{
50 Cfr. Troplong (1846) n. 373 ss.

51 Cfr. Troplong (1846) n. 373 ss.
} 
Lo que ocurre con el artículo 43 es que la obligación de restituir al pasajero el costo que le causó el incumplimiento del proveedor (o su cumplimiento por equivalente) radica en el intermediario, a quien la LPC constituye garante del cumplimiento de esta obligación. El derecho de reembolso contra el proveedor o contra el tercero responsable del incumplimiento que tiene el intermediario según el mismo artículo 43 revela claramente la naturaleza de obligación de garantía que tiene su responsabilidad. El derecho de reembolso está garantizado por el derecho común; el derecho a perseguir la responsabilidad de aquellos por cuyo hecho o culpa el deudor hubiere dejado de cumplir, también (artículo 1677). Por tanto, el intermediario cumple por equivalente la obligación contractual del proveedor restituyendo al consumidor lo que le ha costado el incumplimiento. Es decir, la pretensión del consumidor es al valor de la prestación y no a la prestación en naturaleza.

El consumidor también puede pretender la indemnización de todo perjuicio patrimonial y extrapatrimonial causado por el incumplimiento. Todo indica que la garantía del intermediario también cubre esta obligación. El artículo 43 lo obliga a responder por el incumplimiento; es decir, restituir el valor de la prestación e indemnizar perjuicios al consumidor (que es acreedor de la prestación no cumplida). Esto es concordante con el artículo 41 que permite acumular a la pretensión de cumplimiento, la indemnización: "Sin perjuicio de lo anterior (es decir, del cumplimiento o de la devolución del precio) quedará subsistente la acción del consumidor para obtener la reparación de los perjuicios sufridos".

\section{LAS CAUSAS DE EXONERACIÓN DEL QUE NO HA CUMPLIDO LA OBLIGACIÓN DE HACER UN SERVICIO}

Para terminar este estudio nos preguntamos si los remedios a disposición del acreedor (civil, comercial o consumidor) perderían su eficacia por un incumplimiento no imputable al proveedor o prestador del servicio (por caso fortuito o fuerza mayor), o por un incumplimiento que obedece a la imposibilidad absoluta para la ejecución actual del hecho debido (ex artículos 1547 y 534 Código de Procedimiento Civil). La pregunta es si la imputabilidad y la exoneración de responsabilidad se mueven en un ámbito distinto al del funcionamiento del sistema de responsabilidad contractual expuesto más arriba. Con esto distingo entre "ser responsable" y "estar obligado", como explica Barros Bourie ${ }^{52}$. Pues podría el proveedor o deudor permanecer obligado a satisfacer el interés contractual del acreedor, al menos de algún modo, no siendo responsable de todos los perjuicios que este pueda haber sufrido a causa del incumplimiento, cuando este le es inimputable. El proveedor podría permanecer obligado pero no ser responsable. Este es el análisis que se ofrece a continuación.

\section{A) El CASO FORTUiTO O LA FUERZA MAYOR}

La demanda de restitución del valor de la prestación, a mi juicio, no admite exoneración alguna porque ni el caso fortuito, ni la fuerza mayor, extinguen la obligación. La hipótesis que defiendo en este trabajo es que el caso fortuito exonera de la obligación

52 Cf. Barros Bourie (2006) pp. 721-752. 
de indemnizar porque entonces el incumplimiento no resulta imputable al proveedor por imposibilidad absoluta de ejecución ex artículo 534 del Código de Procedimiento Civil y artículo 1547. (Para el funcionamiento de esta función exoneratoria de responsabilidad, el caso fortuito se equipara a la imposibilidad absoluta de ejecución del hecho.)

Exonerado el deudor de obligación de garantía o responsabilidad, el caso fortuito no necesariamente ha extinguido la obligación: esta subsiste, pero cambia de objeto (ex artículo 1678). Por este mecanismo el proveedor queda obligado al valor de la prestación (un cumplimiento por equivalente). También puede ser obligado a la restitución del precio, si el acreedor opta por pretender la resolución del contrato ex artículo 1489. Puede afirmarse, entonces, que subsisten al menos algunos de los remedios por incumplimiento a disposición del acreedor: una pretensión de cumplimiento por equivalente y una pretensión resolutoria, que tiene por consecuencia la devolución del precio (artículo 1489; artículos 25 y $41 \mathrm{LPC})$. Estos remedios se apoyan en el hecho del incumplimiento, independientemente de su imputabilidad o no imputabilidad al proveedor.

Puede concluirse, entonces, que el caso fortuito tiene la virtualidad de frustrar la pretensión indemnizatoria del acreedor, pero no exonera del cumplimiento ni de otros remedios a disposición de este. El acreedor mantiene la pretensión de cumplimiento, a menos que se haya tornado imposible, y la pretensión resolutoria, para que le restituyan lo dado o pagado con miras a un negocio cuya finalidad se ha frustrado.

\section{B) LA IMPOSIBILIDAD SOBREVINIENTE}

Examinemos cómo podría funcionar la imposibilidad absoluta de ejecución del hecho como defensa del proveedor frente a los diversos remedios a disposición del acreedor por incumplimiento del contrato. Recordaremos que estos son: el cumplimiento en natura o por equivalente, la reducción del precio, la resolución del contrato y la indemnización de perjuicios.

La pretensión de cumplimiento en natura o, en el marco del procedimiento compulsivo, por equivalente, puede paralizarse por imposibilidad absoluta ex artículo 534 del Código de Procedimiento Civil. Me parece que en esto no hay dudas, siempre que tomemos en consideración que tal vez la noción de imposibilidad absoluta de ejecución del hecho no necesariamente equivale aquí a la de caso fortuito. Solo podrían reclamarse ambas nociones si el caso fortuito efectivamente produce una imposibilidad absoluta de ejecución del hecho. De otro modo, la imposibilidad absoluta de ejecución del hecho debido producida por un caso fortuito podría exonerar al deudor también de responsabilidad ${ }^{53}$.

La pretensión resolutoria, sin embargo, no se frustra por imposibilidad absoluta de ejecución del hecho debido. Si el acreedor pretende la resolución del contrato es porque indirectamente aspira por esta vía a obtener la restitución del precio pagado. El proveedor no podría excepcionarse alegando imposibilidad absoluta o caso fortuito, pues no se pretende que cumpla sino que restituya. (Si el contrato no ha sido cumplido por ninguna de las partes, la imposibilidad absoluta de ejecución lo frustra definitivamente: impide la pretensión de cumplimiento y de resolución.)

53 BARAONA (1997) p. 159. 
Por último, como ya hemos dicho anteriormente, el deudor queda exonerado de la pretensión indemnizatoria ex artículo 1547, si la imposibilidad absoluta satisfacen los standards de imprevisibilidad e irresistibilidad del caso fortuito (artículo 45). El baremo formado por estos standards está modelado, como sabemos, por el proyecto negocial de las partes o propósito práctico del contrato.

Esta hipótesis también ha sido defendida desde distintos ángulos por Jorge Baraona y por Álvaro Vidal. Baraona (1997) ${ }^{54}$, que escribe hace ya más de diez años sobre un tema que solo recientemente se ha comenzado a discutir más ampliamente en nuestro país, distingue claramente en el Código la existencia de una pretensión a la aestimatio rei que para él es una pretensión de cumplimiento y la indemnización de daños y perjuicios por el incumplimiento; es decir, reconoce en el Código civil la existencia de dos pretensiones distintas que los autores anteriores a él no diferenciaban tan explícitamente. El caso fortuito para él exonera de la indemnización de daños y perjuicios, no en cuanto elimine la culpa del deudor (o su imputabilidad) sino porque destruye la relación de causalidad entre el hecho del incumplimiento y la persona del deudor. Si se prueba caso fortuito el acreedor pierde la pretensión indemnizatoria pues cae uno de sus supuestos, cual es la relación causal entre hecho del incumplimiento (ilícito) y la persona del deudor ${ }^{55}$. Es decir, para Baraona, el caso fortuito no es la faz negativa de la culpa, de manera que sea legítimo hablar de imputabilidad (faz positiva) y caso fortuito (faz negativa).

Para Vidal (2006), más embebido y formado en una escuela que defiende la responsabilidad contractual estricta, la culpa y el caso fortuito (su faz negativa) inciden solo en el remedio que consiste en la pretensión indemnizatoria, no en los restantes ${ }^{56}$. Sin embargo, este autor admite que la pretensión de cumplimiento específico (que es una pretensión de cumplimiento in natura) exige como presupuesto que la obligación no se haya extinguido por imposibilidad no imputable al deudor ${ }^{57}$. De manera que en caso de imposibilidad, el único remedio que subsiste a disposición del acreedor es la pretensión resolutoria, si por esta vía le interesa obtener la restitución de lo que ha dado o pagado en cumplimiento de un proyecto negocial frustrado. La pretensión resolutoria no exige que el hecho del incumplimiento sea imputable al deudor. Se apoya en el mero hecho del incumplimiento.

Toda esta explicación podríamos ilustrarla con el caso propuesto por Pizarro Wilson (2005) en un estudio realizado hace un par de años ${ }^{58}$. El caso es el de los cortes o racionamientos de suministro de gas a industriales que MetroGas anunció a causa del imprevisto imposible de resistir que consiste en los cortes o racionamientos unilaterales y no pactados de sus proveedores argentinos. MetroGas anunció que no se encontraba en condiciones de servir los contratos de sus clientes industriales a causa de un hecho imprevisto que no le era en absoluto imputable. De esta manera suponemos que pretendía sustraerse de responsa-

\footnotetext{
54 Cfr. Baraona (1997) pp. 151-177.

55 Cfr. Baraona (1997) p. 175

56 VIDAL (2006) p. 203.

57 VIDAL (2006) p. 184.

58 Pizarro Wilson (2005) pp. 115-124.
} 
bilidad por los daños que este incumplimiento ocasionaría a las industrias y exonerarse de millonarias demandas. La pregunta es ¿se sustraía efectivamente?

Para responder a esta pregunta hay que distinguir el funcionamiento de los remedios por incumplimiento (resolución del contrato y devolución de precios pagados, pues no es posible hacer de nuevo el servicio no prestado, ni exigir forzadamente lo que el proveedor no puede cumplir), de la indemnización de todo otro perjuicio. El mero incumplimiento es un hecho que constituye el supuesto de remedios tales como la pretensión de cumplimiento en natura e incluso - por fuerza del procedimiento compulsivo- por equivalente (la pretensión a una condena por aestimatio rei o valor de la prestación), o la pretensión resolutoria, cuya consecuencia es la devolución del precio.

En esta línea se sitúa el artículo 25 de la LPC para los contratos con consumidores, cuando prescribe que durante la paralización de servicios el proveedor no podrá efectuar cobro alguno y estará obligado a restituir al consumidor las tarifas cobradas en proporción al tiempo en que estuvo suspendido el servicio. La suspensión o paralización del suministro es un incumplimiento que ofrece al consumidor un remedio específico adecuado a su interés: la devolución del precio. Podría decirse que el contrato se "resuelve" o "suspende" mientras dura la paralización, sin perjuicio del derecho del consumidor de resolverlo y cambiarse de proveedor si el mercado le permite esta opción. No son funcionales a este supuesto los otros remedios a su disposición: el cumplimiento en natura o la reiteración del servicio.

No existe una norma semejante para contratos entre industriales: rigen las reglas comunes que permiten al acreedor el recurso a la pretensión resolutoria. Si no existen alternativas de suministro en el mercado, esta pretensión deberá adecuarse a las circunstancias del contrato. La LPC discurre sobre un supuesto de resolución parcial o suspensión en el tiempo de un contrato de tracto sucesivo o de cumplimiento continuo.

Cosa aparte es que los acreedores pretendan la indemnización de todo otro daño causado por el incumplimiento. Entonces cabría analizar si caben causas de exoneración del deudor: este es el análisis realizado por Pizarro Wilson en su trabajo, donde arriba a la conclusión de que los cortes de suministro no constituyen fuerza mayor que permita a MetroGas exonerarse de responsabilidad.

No son fuerza mayor, efectivamente, porque no satisfacen el standard de irresistibilidad, ni -posiblemente- el de imprevisibilidad ${ }^{59}$. Los racionamientos o cortes argentinos no son causa necesaria del incumplimiento (el hecho irresistible no incide necesariamente en el incumplimiento) ni pueden considerarse hechos imprevisibles al tiempo del contrato. Pues, en efecto, MetroGas pudo prever los racionamientos o cortes argentinos al tiempo de contratar, y puede proveerse de otras fuentes aunque le supongan un abastecimiento más caro y menores márgenes de utilidad en su gestión. El incumplimiento sería de todos modos imputable a su falta de diligencia y obligaría al proveedor a indemnizar todos los daños que estaban dentro de su esfera de control (esta es la regla de la previsibilidad que ofrece el artículo 1558) y que pudo evitar con un cumplimiento puntual y completo de la obligación. De manera que MetroGas está también obligado a indemnizar todo daño causado por su incumplimiento.

59 Sobre estos requisitos, por todos, AlESSANDri (2005) p. 435. 
Este caso podría servir también para ilustrar la diferencia de grado entre la imposibilidad absoluta de ejecución del hecho (suministro de gas a industriales y particulares) y el caso fortuito. La evolución posterior del caso demuestra que los cortes o racionamientos argentinos no han significado una imposibilidad absoluta de ejecución del hecho, pues MetroGas ha podido abastecerse por mecanismos alternativos de emergencia. La economía de los contratos de suministro había previsto estas situaciones. La cuestión de si configuran un supuesto de fuerza mayor (si satisfacen los standards de irrestibilidad e imprevisibilidad) es asunto aparte. Para que constituyan fuerza mayor habría que examinar en concreto el propósito práctico que perseguían las partes al contratar y todas las circunstancias previstas por ellas al tiempo del contrato. Si según la regla formada por todos estos elementos los cortes eran imprevisibles e irresistibles, entonces aceptaríamos la defensa de fuerza mayor que estaría a disposición del proveedor frente a la pretensión indemnizatoria de sus acreedores.

\section{CONCLUSIONES}

Las consecuencias jurídicas o responsabilidad por el incumplimiento de contratos de servicios son las siguientes. Primero, el derecho del acreedor o consumidor a pedir que se haga de nuevo el servicio; es decir, que se vuelva a cumplir el contrato o que se subsane el incumplimiento. Segundo, el derecho del acreedor a pedir la devolución del precio; es decir, el derecho a pedir la resolución del contrato por incumplimiento. Tercero, el derecho a pedir indemnización de perjuicios por el incumplimiento. Este conjunto de pretensiones forma un sistema de responsabilidad contractual por incumplimiento de contratos que engendran obligaciones de hacer, como los contratos de prestación de servicios. En la medida que este conjunto de pretensiones está asegurado por leyes generales (Código Civil y de Comercio) y especiales (LPC, D.L. No 458 de 1976 sobre Urbanismo y Construcciones), tanto para acreedores civiles o mercantiles como para consumidores, puede afirmarse que los contratos de prestación de servicios también cuentan con una garantía legal por incumplimiento.

Estas consecuencias jurídicas son generalmente de uso alternativo o de opción para el acreedor o consumidor. Sin embargo, según la naturaleza del hacer comprometido en el contrato, hay supuestos en que no es posible la opción y el acreedor o consumidor solamente puede pedir la indemnización de perjuicios. Son casos en que no puede volver a hacerse el servicio. O casos en que no cabe restitución del precio porque no puede deshacerse lo hecho. La indemnización de perjuicios tiene, por esto, especial relevancia como mecanismo de aseguramiento de la responsabilidad por incumplimiento de contratos de prestación de servicios. Este último mecanismo exige un juicio contradictorio en que se pruebe la especie y cuantía del daño, como asimismo que este resulta imputable causal y subjetivamente al deudor.

Un caso especial en que se atribuye responsabilidad contractual al intermediario de un contrato de prestación de servicios es el caso del artículo 43 LPC. El supuesto responde a la tendencia en el Derecho del Consumo de elevar a la categoría de norma imperativa determinados pactos que admite el derecho común de los contratos. En este caso, el pacto por el cual el intermediario se constituye garante como deudor principal frente al mandatario o agente del credere. 
Una conclusión de este estudio es, por último, que el deudor responde por el incumplimiento sin que pueda exonerarse de responsabilidad alegando caso fortuito o fuerza mayor; y ni siquiera imposibilidad sobreviniente. Estas alegaciones pueden hacerse valer; pero tienen finalidades limitadas. Este estudio considera que nunca liberan totalmente al deudor de su responsabilidad.

\section{BIBLIOGRAFÍA CITADA}

Abeliuk Manasevich, René (2008): Las obligaciones (Santiago, Editorial Jurídica de Chile, quinta edición).

Alessandri Rodríguez, Arturo (2003): De la Compraventa y de la Promesa de venta (Santiago, Editorial Jurídica de Chile, reimpresión de la primera edición).

Alessandri Rodríguez, Arturo (2005): De la responsabilidad extracontractual en el Derecho Civil chileno (Santiago, Editorial Jurídica de Chile (reimpresión de la primera edición de 1943).

Alessandri Rodríguez, Arturo; Somarriva Undurraga, Manuel y Vodanovic Haklicka, Antonio (2004a): Tratado de las obligaciones. De las obligaciones en general y sus diversas clases (Santiago, Editorial Jurídica de Chile, segunda edición ampliada y actualizada).

Alessandri Rodríguez, Arturo; Somarriva Undurraga, Manuel y Vodanovic Haklicka, Antonio (2004b): Tratado de las obligaciones. Cumplimiento e incumplimiento de las obligaciones. De la protección de los derechos del acreedor. De la insolvencia y las formas de pago de los deudores insolventes (Santiago, Editorial Jurídica de Chile, segunda edición ampliada y actualizada).

BaraOna GonZÁlez, Jorge (1997): "Responsabilidad contractual y factores de imputación de perjuicios: apuntes para una relectura en clave objetiva", en Revista Chilena de Derecho, vol. $24 \mathrm{~N}^{\circ} 1$ : pp. 151-177.

Barendrecht, J. M. (dir.) et al. (2007): Service Contracts. PEL SC (Principles of European Law. Service Contracts) (Oxford, Oxford University Press).

Barrientos Zamorano, Marcelo (2010): "Jurisprudencia por daños en estacionamiento de vehículos regido por la ley del consumidor", en Revista de Derecho de la Pontificia Universidad Católica de Valparaíso XXXIV: pp. 39-73.

Barros Bourie, Enrique (2006) "La diferencia entre estar obligado y ser responsable en el derecho de los contratos", en Estudios de Derecho Civil II (Santiago, LegalPublishing) pp. 721-752.

Barros Bourie, Enrique (2011) "Los contratos de servicios ante la doctrina general del contrato: la virtualidad analógica de las reglas del mandato", en ELORRIAGA DE BONIS, Fabián (Coord.), en Estudios de Derecho Civil VII (Santiago, AbeledoPerrot) pp. 325-340.

Cabanillas Sánchez, Antonio (1993): Las obligaciones de actividad y de resultado (Barcelona, Bosch).

Contardo González, Juan Ignacio (2010): Responsabilidad civil contractual de las agencias de viajes (Santiago, AbeledoPerrot).

Contardo González, Juan Ignacio (2012): El perjuicio resolutorio. Delimitación y cuantía de la indemnización de perjuicios consagrada en el artículo 1489 del Código Civil en caso 
de resolución por incumplimiento (Santiago, tesis doctoral inédita en depósito: Biblioteca de la Universidad de los Andes).

Corral Talciani, Hernán (2006) "La responsabilidad por incumplimiento y por productos peligrosos en la ley de protección de los derechos de los consumidores", en BARAONA González, Jorge y Lagos Villarreal, Osvaldo (ed.), La protección de los derechos de los consumidores en Chile. Aspectos sustantivos y procesales luego de la reforma contenida en la ley $N^{\circ} 19.955$ de 2004, Cuadernos de Extensión Jurídica 12 (Santiago, Ediciones Universidad de los Andes) pp. 95-110.

Corral Talciani, Hernán (2009): "El concurso de responsabilidades en el Derecho de daños chileno. Defensa y delimitación de la teoría de la opción”, en Estudios de Derecho Civil V(Santiago, AbeledoPerrot) pp. 639-653.

Corral Talciani, Hernán (2010): Contratos y daños por incumplimiento (Santiago, Abeledo Perrot).

Díez-Picazo, Luis (1996): Fundamentos del Derecho Civil Patrimonial. I. Introducción. Teoría del contrato (Civitas, Madrid, quinta edición).

Díez-Picazo, Luis (2008): Fundamentos del Derecho civil patrimonial. II. Las relaciones obligatorias (Madrid, Thompson-Civitas, sexta edición).

FueYo, Fernando (1991): Cumplimiento e incumplimiento de las obligaciones (Santiago, Editorial Jurídica de Chile, segunda edición).

García González, Alejandro (2002): Responsabilidad civil contractual. Obligaciones de medios y de resultados (Santiago, ConoSur).

López DíAz, Pamela (2010): "La indemnización compensatoria por incumplimiento de los contratos bilaterales como remedio autónomo en el Derecho Civil chileno", en Revista Chilena de Derecho Privado, N 15: pp. 65-113.

López Santa María, Jorge (1998): Los Contratos. Parte General (Santiago, Editorial Jurídica de Chile).

Morales Moreno, Antonio Manuel (2006): "Pretensión de cumplimiento y pretensión indemnizatoria”, en La modernización del Derecho de obligaciones (Madrid, Civitas) pp. 55-92.

Morales Moreno, Antonio Manuel (2006): La modernización del Derecho de obligaciones (Madrid, Civitas).

Ortí Vallejo, Antonio et al. (2006): La responsabilidad civil por daños causados por servicios defectuosos. Daños a la salud y seguridad de las personas (Madrid, Thomson/Aranzadi).

Pantaleón Prieto, Fernando (1993): "Las nuevas bases de la responsabilidad contractual" en Anuario de Derecho Civil, vol. 46 N 4: pp. 1719-1746.

Parra LuCÁN, María Ángeles (2011): La protección del consumidor frente a los daños. Responsabilidad civil del fabricante y del prestador de servicios (Madrid, Reus).

Peñailillo Arévalo, Daniel (2006): Obligaciones. Teoría general y clasificaciones. La resolución por incumplimiento (Santiago, Editorial Jurídica de Chile).

Pizarro Wilson, Carlos (2005): "La fuerza mayor como defensa del deudor. A propósito de la restricción de suministro de gas a Chile", en Revista de Derecho Administrativo Económico, $\mathrm{N}^{\circ}$ 14: pp. 115-124. 
Pizarro Wilson, Carlos (2008): "La culpa como elemento constitutivo del incumplimiento en las obligaciones de medio o de diligencia", en Revista de Derecho de la Pontificia Universidad Católica de Valparaiso XXXI: pp. 255-265.

Troplong (1846): Du mandat. Commentarire du Titre XIII du Livre III du Code Civil (Paris). Vial del Río, Víctor (2007): Manual de las obligaciones en el Código Civil chileno (Santiago, Editorial Biblioteca Americana).

Vidal Olivares, Álvaro (2006): La protección del comprador. Régimen de la Convención de Viena y su contraste con el Código Civil (Valparaíso, Ediciones Universitarias).

Vidal Olivares, Álvaro (2007): "Cumplimiento e incumplimiento contractual en el Código Civil. Una perspectiva más realista”, en Revista Chilena de Derecho, vol. $34 \mathrm{~N}^{\circ}$ 1: pp. 41-59.

Villanueva Lupión, Carmen (2009a): El servicio como objeto de tráfico jurídico (Madrid, La Ley).

Villanueva Lupión, Carmen (2009b): Los contratos de servicios (Madrid, La Ley).

\section{NORMAS LEGALES CITADAS}

Directiva 2006/123/CE del Parlamento Europeo y del Consejo de 12 de diciembre de 2006 relativa a servicios en el mercado interior.

Código Civil chileno, artículos 565, 581, 1487, 1489, 1537, 1545, 1547, 1553, 1555, $1556,1557,1558,1559,1560,1567,1568,1569,1672,1677,1698,1810,1996$, 1997, 1998, 1999, 2002, 2005, 2006 a 2012, 2013 a 2021, 2118, 2152, 2219.

Código de Comercio, artículos 233 y siguientes.

Código de Procedimiento Civil chileno, artículo 534.

Ley $\mathrm{N}^{\circ} 19.496$, de 1997, sobre protección de los derechos de los consumidores, artículos 2, $312,21,23,25,40,41,42,43,44,45,46,47,55$ a $56 \mathrm{H}$.

Ley $\mathrm{N}^{\circ}$ 18.290, de 1984, Ley del tránsito, artículo 174.

\section{JURISPRUDENCIA CITADA}

Bravo con Preuniversitario Pedro de Valdivia (2005): Primer Juzgado de Policía Local de Puerto Montt, 6 de diciembre de 2005, Rol 3400 (disponible en http://www.sernac.cl/ category/sentencias-judiciales/ visitado el 19 de marzo de 2013).

Carmen Roig con Empresa Corredora de Seguros Andueza y Cía. Ltda. (2004): Corte de Valparaíso, 10 de junio de 2004. LegalPublishing $N^{\circ} 30832$.

Centro de Arbitraje y Mediación de Santiago (CAM Santiago) (2006): Sentencia de 26 de octubre de 2006, Rol 574 (Juan Eduardo Figueroa Valdés).

Centro de Arbitraje y Mediación de Santiago (CAM Santiago) (2008): Sentencia de 25 de septiembre de 2008, Rol 772 (Gonzalo Fernández Ruiz, Árbitro arbitrador).

Elizalde con Sociedad Comercial (2009): Corte Suprema, 17 de noviembre de 2009, Repertorio electrónico LegalPublishing 42896.

Grunwald con Agencia de Viajes Tije Chile S.A. (2008): Corte Suprema, 3 de septiembre de 2008. Rol 3130-08 (disponible en http://www.sernac.cl/category/sentencias-judiciales/ visitado el 19 de marzo de 2013). 
Hiller con Comercial Bas S.A. (2008): Corte Suprema, 15 de julio de 2008, N LegalPublishing: 39564.

Hübner con Agencia Eurotour Ltda. (1998): Tercer Juzgado de Policía Local de Santiago, 2 de febrero de 1998 (disponible en http://www.sernac.cl/category/sentencias-judiciales/ visitado el 19 de marzo de 2013).

Inmobiliaria e Inversiones con Salazar Berrocal y otra (2010): Corte Suprema (Primera Sala), 13 de diciembre de 2010 (cumplimiento de contrato con indemnización de perjuicios), $\mathrm{N}^{\circ}$ LegalPublishing: 47642.

Jacob Jure con SmartCom PCS (2008): Corte de Apelaciones de La Serena, 27 de agosto de 2008, Repertorio electrónico LegalPublishing 39737.

Karina Valenzuela con Turismo Cocha S.A. (2007): Corte de Apelaciones de Santiago, 6 de diciembre de 2007. LegalPublishing 37848.

Lobos con Allendes (2008): Tercer Juzgado de Policía Local de Iquique, 20 de agosto de 2008, Rol 749 (disponible en http://www.sernac.cl/category/sentencias-judiciales/ visitado el 19 de marzo de 2013).

Mejías con Turismo Zahr (2008): Corte de Apelaciones Valparaíso, 1 de diciembre de 2008. LegalPublishing $\mathrm{N}^{\circ} 41334$.

Meneses con Bellsouth (2006): Corte de Apelaciones Santiago, 10 de mayo de 2006, Rol 103-2006 (disponible en http://www.sernac.cl/category/sentencias-judiciales/ visitado el 19 de marzo de 2013).

Moreira con Vera (2010): Juzgado de Policía Local de Puerto Montt, 28 de febrero de 2010, Rol 5638 (disponible en http://www.sernac.cl/category/sentencias-judiciales/ visitado el 19 de marzo de 2013).

Opazo con Inmunomédica (2010): Corte Suprema (Primera Sala), 7 de diciembre de 2010 (resolución de contrato con indemnización de perjuicios), $\mathrm{N}^{\circ}$ LegalPublishing: 47448.

Pacheco con Tije Chile S.A. (2008): Corte de Apelaciones Santiago, 6 de agosto de 2008. LegalPublishing 39601.

Romeo Viajes Limitada (2007): Corte de Apelaciones Valparaíso, 13 de noviembre de 2007. LegalPublishing 37658.

Sernac con Aguas Chañar S.A. (2011): Cuarto Juzgado de Letras de Copiapó, Rol 14232011 (causa pendiente).

Urra con Tije Chile S.A. (2007): Juzgado de Policía Local de Providencia, 11 de septiembre de 2007, Rol 2607-04-2007 (disponible en http://www.sernac.cl/category/sentenciasjudiciales/ visitado el 19 de marzo de 2013). 
